\title{
(2) \\ EULAR points to consider for the management of difficult-to-treat rheumatoid arthritis
} OPEN ACCESS

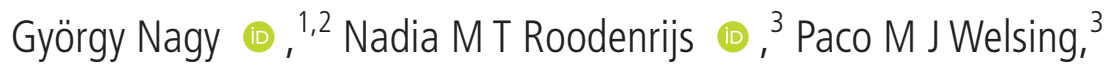

Melinda Kedves (1) , ${ }^{4}$ Attila Hamar (1) , ${ }^{5}$ Marlies C van der Goes, ${ }^{3,6}$ Alison Kent, ${ }^{7}$ Margot Bakkers, ${ }^{8}$ Polina Pchelnikova, ${ }^{8}$ Etienne Blaas, ${ }^{3}$ Ladislav Senolt, ${ }^{9}$ Zoltan Szekanecz 이, ${ }^{5}$ Ernest H Choy $10,{ }^{10}$ Maxime Dougados, ${ }^{11}$ Johannes WG Jacobs 이, ${ }^{3}$ Rinie Geenen, ${ }^{12}$ Johannes WJ Bijlsma (1), ${ }^{3}$ Angela Zink, ${ }^{13}$ Daniel Aletaha (1), ${ }^{14}$ Leonard Schoneveld, ${ }_{1}^{15}$ Piet van Riel, ${ }_{1}^{16}$ Sophie Dumas, ${ }_{1}^{17}$

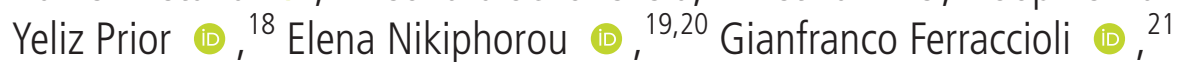
Georg Schett 우, ${ }^{22}$ Kimme L Hyrich 이, ${ }^{23,24}$ Ulf Mueller-Ladner, ${ }^{25}$ Maya H Buch 주, ${ }^{23,24,26}$ lain B McInnes, ${ }^{27}$ Désirée van der Heijde (다, ${ }^{28}$ Jacob M van Laar (1) $^{3}$

Handling editor Dimitrios T Boumpas

For numbered affiliations see end of article.

\section{Correspondence to} Professor György Nagy, Department of Rheumatology \& Clinical Immunology, Semmelweis University, Árpád fejedelem útja 7, 1023, Budapest, Hungary; nagy.gyorgy2@med. semmelweis-univ.hu

GN and NMTR contributed equally.

DvdH and JMvL contributed equally.

GN and NMTR are joint first authors.

DvdH and JMvL are joint senior authors.

Received 12 June 2021 Accepted 23 July 2021

Check for updates

(c) Author(s) (or their employer(s)) 2021. Re-use permitted under CC BY-NC. No commercial re-use. See rights and permissions. Published by BMJ.

\begin{tabular}{l}
\hline To cite: Nagy G, \\
Roodenrijs NMT, \\
Welsing PMJ, et al. \\
Ann Rheum Dis Epub ahead \\
of print: [please include Day \\
Month Year]. doi:10.1136/ \\
annrheumdis-2021-220973 \\
\hline
\end{tabular}

\section{ABSTRACT}

Objective To develop evidence-based European Alliance of Associations for Rheumatology (EULAR) points to consider (PtCs) for the management of difficultto-treat rheumatoid arthritis (D2T RA).

Methods An EULAR Task Force was established comprising 34 individuals: 26 rheumatologists, patient partners and rheumatology experienced health professionals. Two systematic literature reviews addressed clinical questions around diagnostic challenges, and pharmacological and nonpharmacological therapeutic strategies in D2T RA. PtCs were formulated based on the identified evidence and expert opinion. Strength of recommendations (SoR, scale A-D: A typically consistent level 1 studies and D level 5 evidence or inconsistent studies) and level of agreement (LoA, scale 0-10: 0 completely disagree and 10 completely agree) of the PtCs were determined by the Task Force members.

Results Two overarching principles and $11 \mathrm{PtCs}$ were defined concerning diagnostic confirmation of RA, evaluation of inflammatory disease activity, pharmacological and non-pharmacological interventions, treatment adherence, functional disability, pain, fatigue, goal setting and self-efficacy and the impact of comorbidities. The SoR varied from level $C$ to level $D$. The mean LoA with the overarching principles and PtCs was generally high (8.4-9.6).

Conclusions These PtCs for D2T RA can serve as a clinical roadmap to support healthcare professionals and patients to deliver holistic management and more personalised pharmacological and non-pharmacological therapeutic strategies. High-quality evidence was scarce. A research agenda was created to guide future research.

\section{INTRODUCTION}

Treatment options for rheumatoid arthritis (RA) have expanded with availability of biological and targeted synthetic disease-modifying antirheumatic drugs (b/tsDMARDs). ${ }^{1}$ The updated European League Against Rheumatism (EULAR, from 2021, European Alliance of Associations for
Rheumatology) recommendations for the management of RA $^{2}$ focusing on pharmacological therapy are similar to those developed by other international organisations. ${ }^{3-5}$ Other recommendations and points to consider (PtCs) provide specific management support on cardiovascular disease (CVD) risk, ${ }^{6}$ comorbidities, ${ }^{7}$ imaging, ${ }^{8}$ pain ${ }^{9}$ and patient education. ${ }^{10}$ Together with implementation of treat-to-target and tight control strategies, ${ }^{2}{ }^{11}$ specifically in the early phase of the disease, these have contributed to improved outcomes for the majority of patients with RA.

However, some patients with RA do not reach low disease activity or remission and/or remain symptomatic after several cycles of conventional synthetic (cs) DMARDs, bDMARDs and/or tsDMARDs. ${ }^{12-14}$ Such patients may be referred to as having 'difficult-to-treat (D2T)' disease. Optimal management of these patients poses a significant challenge in clinical practice. ${ }^{15}$ Hitherto, no specific guidance has been developed for the management of this complex patient population. Therefore, an EULAR Task Force was convened to develop PtCs for the management of D2T RA.

\section{METHODS}

\section{Steering Committee and Task Force}

The convenor (GN) and co-convenor (JMvL) formed the Steering Committee and Task Force that followed the EULAR standardised operating procedures (SOPs). ${ }^{16}$ The Steering Committee included the (co-)convenors, a methodologist $(\mathrm{DvdH})$, a co-methodologist (PMJW), a rheumatology postdoctoral fellow (Maria J H de Hair) and three fellows (NMTR, MK and AH). The Task Force comprised the Steering Committee members and another 18 rheumatologists (including 2 EMerging EUlar Network representatives), 3 patient partners, 1 rheumatology nurse, 1 rheumatology occupational therapist, 1 psychologist and 2 pharmacists. All rheumatologists were experienced in the treatment of RA, the majority with significant experience in clinical trials and some also in outcomes 


\section{Box 1 Definition of D2T RA ${ }^{17}$}

All three criteria need to be present in D2T RA:

1. Treatment according to EULAR recommendations and failure of $\geq$ two b/tsDMARDs (with different mechanisms of action) $\dagger$ after failing csDMARD therapy (unless contraindicated). $\dagger$

2. Signs suggestive of active/progressive disease, defined as zone of:

a. At least moderate disease activity (according to validated composite measures including joint counts, for example, DAS28-ESR >3.2 or CDAI >10).

b. Signs (including acute phase reactants and imaging) and/ or symptoms suggestive of active disease (joint related or other).

c. Inability to taper glucocorticoid treatment (below $7.5 \mathrm{mg} /$ day prednisone or equivalent).

d. Rapid radiographic progression (with or without signs of active disease). $¥$

e. Well-controlled disease according to above standards, but still having RA symptoms that are causing a reduction in quality of life.

3. The management of signs and/or symptoms is perceived as problematic by the rheumatologist and/or the patient.

b/tsDMARDs, biological and targeted synthetic disease-modifying antirheumatic drugs; CDAl, Clinical Disease Activity Index; csDMARD, conventional synthetic disease-modifying antirheumatic drug; D2T, difficult-to-treat; DAS28-ESR, Disease Activity Score assessing 28 joints using erythrocyte sedimentation rate; RA, rheumatoid arthritis. tUnless restricted by access to treatment due to socioeconomic factors. tIf csDMARD treatment is contraindicated, failure of $\geq$ two b/tsDMARDs with different mechanisms of action is sufficient.

¥Rapid radiographic progression: change in van der Heijde-Modified Sharp Score $\geq 5$ points in 1 year ${ }^{184}$ or a similar progression in another validated scoring method.

research and patient registries. All 34 Task Force members declared their potential conflicts of interest before the start of the project. Two of the Task Force members (Maria J H de Hair and Loriane Gutermann (pharmacist)) left the Task Force during the process, due to new positions, and did not attend the second and third Task Force meetings.

\section{Target audience}

In accordance with the EULAR SOP, the primary target audience of these PtCs is healthcare professionals (HCPs) and patients (and their carers). ${ }^{16}$ In addition, these PtCs may serve to highlight unmet needs in D2T RA and, therefore, also target policy-makers, pharmaceutical and health insurance companies.

\section{Definition}

As an initial step, a definition and a uniform term for the patient population had to be established. The Steering Committee proposed terminology and created a first draft of a definition, guided by the results of the international survey and a scoping literature review. ${ }^{15}$ These were discussed with the whole Task Force and amended during the first Task Force meeting (held in August 2018). The final terminology and definition were agreed by a voting process. All Task Force members agreed with 'D2T RA' as the term and the final definition (box 1$).{ }^{17}$

\section{Clinical questions and systematic literature reviews}

The Steering Committee formulated the clinical questions for the systematic literature reviews (SLRs). Clinical questions focused on techniques for the confirmation of the diagnosis of RA and/or a relevant differential diagnosis (either as alternative (ie, misdiagnosis) or coexisting disease mimics). Additional questions centred around the assessment of inflammatory activity in patients with RA in general and in those with specific comorbidities, which may influence this assessment, adherence, pharmacological and non-pharmacological therapeutic strategies for different aspects of D2T RA: patients with limited DMARD choices because of adverse events, comorbidities or other contraindications; patients in whom at least two b/ tsDMARD with different mechanisms of action (MOA) failed; and patients with predominantly non-inflammatory complaints (not directly related to inflammation). In addition, the therapeutic role of lifestyle interventions, of goal setting between patients and HCPs and of self-management was assessed. All questions were discussed and finalised during the first Task Force meeting.

SLRs on these questions were performed by the fellows (NMTR, MK and AH) under supervision of the co-methodologist (PMJW) in accordance with the EULAR SOP. ${ }^{16}$ As other ongoing EULAR projects were already focusing on adherence and lifestyle factors, it was decided not to perform separate SLRs on these topics, but to refer to the respective SLRs and PtCs. ${ }^{1819}$ For the other questions, PubMed, Embase and Cochrane bibliographic databases were searched for relevant papers until December 2019, as well as EULAR and American College of Rheumatology (ACR) conference abstracts from 2017 up to and including 2019. Relevant papers were selected and critically appraised. Results were summarised, including assessment of risk of bias (RoB). ${ }^{16}$ Further details on the methodology and results of the SLRs are published separately. ${ }^{20} 21$

\section{Consensus finding}

Based on the results of the SLRs, draft of overarching principles and PtCs were proposed. The results of the SLRs as well as the proposed overarching principles and PtCs were considered, then presented by the Steering Group and discussed at three consecutive online meetings (the second Task Force meeting was split into three different online meetings) of the Task Force in September 2020 and October 2020. Twenty-five, 30 and 27 Task Force members, respectively, participated in these online meetings. Thereafter, overarching principles and PtCs were discussed and amended.

A voting process was applied per PtC. In round 1, a majority of at least $75 \%$ was required to accept the PtC. If this was not achieved, the $\mathrm{PtC}$ was discussed and amended and subjected to the second ballot. In round 2, a majority of at least $66 \%$ was required to accept the rephrased $\mathrm{PtC}$. If this was not achieved, the $\mathrm{PtC}$ was discussed and amended again and subjected to the third ballot. In round 3, a majority of at least 50\% was required to accept the rephrased PtC. If this was not achieved, the PtC was rejected.

After the meeting, the level of evidence (LoE) and strength of recommendations (SoR) according to the Oxford Centre for Evidence-Based Medicine system were determined. ${ }^{22}$ The agreed overarching principles and PtCs were distributed among all Task Force members via email to assess their level of agreement (LoA) for each PtC. LoA was anonymously scored on a scale from 0 to 10 (0: completely disagree and 10: completely agree). LoA is shown as mean (SD) and as the proportion of Task 
Force members with an LoA of at least 8. Additionally, a research agenda was created.

All Task Force members reviewed the draft of the manuscript. Thereafter, the manuscript was submitted to the EULAR Quality of Care Committee and the EULAR Council for review and approval. A third virtual meeting was held in April 2021 to discuss the comments by the EULAR Council, with 30 Task Force members in attendance. The manuscript was revised and the final version was submitted to EULAR and subsequently to the journal.

\section{RESULTS}

\section{General aspects}

Due to the scarcity of high-quality evidence (table 1), we prepared 'PtCs' for the management of D2T RA. Our PtCs complement current EULAR recommendations that also address elements of management of D2T RA. ${ }^{2}$ The SLRs and the formulation of the PtCs predominantly focused on topics not addressed previously and refer to several published ${ }^{2-10}{ }^{23-25}$ and ongoing EULAR projects where appropriate. $^{19}$

The discussion of the Task Force resulted in 2 overarching principles and $11 \mathrm{PtCs}$ (table 1). The LoE ranged from 3 to 5 and the SoR ranged from $\mathrm{C}$ to $\mathrm{D}$, predominantly, because highquality evidence derived in the population of interest was scarce. The LoA was generally high and ranged from 8.4 to 9.6. The order of PtCs was presented in what was considered as logical sequence-in particular the first two PtCs, which serve as a basis for all subsequent items. The PtCs as presented can be used as a clinical roadmap (figure 1). Below, a point-by-point discussion is presented, explaining the reasoning behind the different topics and the supporting evidence.

\section{Overarching principles}

The Task Force formulated the following overarching principles.

(A) These PtCs pertain to patients who fulfil the definition of $D 2 T R A$ and are underpinned by the EULAR recommendations for the management of $R A$ including the overarching principles (LoA: $9.6(1.0)) .^{2} 17$

This principle emphasises the relationship between these PtCs and the EULAR definition of D2T RA. ${ }^{17}$ All overarching principles and EULAR recommendations for the management of RA also apply to D2T RA. ${ }^{2}$ Patients who fail at least two b/ tsDMARDs with different MOA, and are, therefore, potentially classified as having D2T RA, fall in phase III of the management algorithm of the 2019 EULAR RA management recommendations. These D2T RA PtCs, therefore, provide further guidance on factors contributing to the D2T RA state. The Task Force unanimously agreed with this overarching principle $(100 \%$ agreed, first round, $\mathrm{n}=27$ ).

(B) The presence or absence of inflammation should be established to guide pharmacological and non-pharmacological interventions (LoA: 9.5 (1.3)).

The Task Force emphasised that confirming the presence of inflammatory RA disease activity is essential and should be done prior to adjustment of DMARD therapy. If the persistence of signs and/or symptoms is not caused by RA disease activity, DMARD therapy would in all probability be ineffective and may lead to apparent failure of multiple (b/ts)DMARDs. Concomitant fibromyalgia, osteoarthritis and/or psychological conditions, non-adherence, and comorbidities (eg, infections and malignancies) may contribute to the D2T state. ${ }^{13}{ }^{26}$ Moreover, when the presence of inflammatory activity has been ascertained, the coexistence and role of these factors should be considered. It was agreed that in the absence of inflammatory activity, DMARD therapy should not be escalated (figure 1), and careful tapering might be considered. This overarching principle was accepted in the second round of the voting process $(78 \%$ agreed, second round, $n=24)$.

\section{Points to consider}

(1) If a patient has a presumed D2T RA, the possibility of misdiagnosis and/or the presence of a coexistent mimicking disease should be considered as a first step (LoE: 5, SoR: D, LoA: 9.3 (1.2)).

An accurate RA diagnosis is the cornerstone of appropriate management. In the SLR, very few studies could be identified on this clinically relevant item. ${ }^{20-31}$ Consequently, this $\mathrm{PtC}$ is based on expert opinion, reinforced by indirect evidence.

Misdiagnosis (ie, an alternative disease mimic) may be more common in seronegative disease, ${ }^{32} 33$ but should be considered in all patients with D2T RA. Several diseases may mimic ongoing RA disease activity, such as: crystal arthropathies, polymyalgia rheumatica, psoriatic arthritis, spondyloarthritis, Still's disease, systemic lupus erythematosus, Rhupus (RA-lupus) syndrome, idiopathic inflammatory myopathies, vasculitis, remitting symmetric seronegative synovitis and pitting oedema, reactive arthritis (eg, parvo B19, rubella, Whipple's disease and hepatitis $B$ virus (HBV) and hepatitis $\mathrm{C}$ virus (HCV) infections), paraneoplastic syndromes, osteoarthritis and fibromyalgia. ${ }^{134}$ Furthermore, such other conditions may coexist and underlie signs and/ or symptoms suggestive of active RA.

Current RA management approaches may also lead to misdiagnosis. Based on the 'window of opportunity', 35 EULAR and other international guidelines emphasise the importance of early diagnosis and immediate DMARD initiation to achieve optimal and sustained benefit. ${ }^{2} 3$ However, this raises the possibility of misdiagnosis. ${ }^{36}$ In this context, an RA treatment approach would inevitably lead to apparent inefficacy and unnecessary risk of toxicity.

The Task Force unanimously agreed with this PtC (100\% agreed, first round, $\mathrm{n}=24$ ).

(2) Where there is doubt on the presence of inflammatory activity based on clinical assessment and composite indices, ultrasonography (US) may be considered for this evaluation (LoE: 4, SoR: C, LoA: 9.2 (1.4)).

This $\mathrm{PtC}$ is linked closely to overarching principle $\mathrm{B}$. In daily practice, composite indices (at patient level) and the clinical evaluation of a joint being swollen (at joint level) are most frequently used to assess the presence of inflammatory disease activity. ${ }^{2}$ However, in patients with D2T RA in whom there is a doubt about the presence of inflammation ${ }^{37}$ (see also $\mathrm{PtC} \# 1$ ), these traditional measures may be difficult to interpret.

Limited (high-quality) evidence was found on diagnostics that can be used to assess the presence or absence of inflammatory disease activity in this patient group. ${ }^{20}$ When traditional measures are challenging, US appears to be the most feasible measure to detect inflammatory activity both in patients with D2T RA in general and in those with conditions that might compound assessment, such as obesity or concomitant fibromyalgia. In the general population of RA (where composite indices can be considered reliable), moderate-to-strong correlations were reported between US sum scores and composite indices on a group level. ${ }^{38-45}$ In a study in established patients with RA in whom there was explicit doubt about the presence of inflammation, only weak and non-statistically significant correlations between US sum scores and composite indices were found. ${ }^{46}$ 
Table 1 EULAR PtCs for the management of D2T RA

\begin{tabular}{|c|c|c|c|c|c|}
\hline & & $\operatorname{LoE}^{22}$ & $\mathrm{SoR}^{22}$ & LoA mean (SD) & $\geq 8 / 10(\%)$ \\
\hline & Overarching principles & & & & \\
\hline A & $\begin{array}{l}\text { These PtCs pertain to patients who } \\
\text { fulfil the definition of D2T RA and } \\
\text { are underpinned by the EULAR } \\
\text { recommendations for the management } \\
\text { of RA, including the overarching } \\
\text { principles. }{ }^{217}\end{array}$ & NA & NA & $9.6(1.0)$ & 97 \\
\hline B & PtCs & & & & \\
\hline 1 & $\begin{array}{l}\text { If a patient has a presumed D2T RA, } \\
\text { the possibility of misdiagnosis and/or } \\
\text { the presence of a coexistent mimicking } \\
\text { disease* should be considered as a first } \\
\text { step. }\end{array}$ & 5 & D & $9.3(1.2)$ & 91 \\
\hline 3 & $\begin{array}{l}\text { Composite indices and clinical evaluation } \\
\text { should be interpreted with caution in the } \\
\text { presence of comorbidities }{ }^{\ddagger} \text { in particular } \\
\text { obesity and fibromyalgia }{ }^{\S} \text { as these may } \\
\text { directly heighten inflammatory activity } \\
\text { and/or overestimate disease activity. }\end{array}$ & $\begin{array}{l}{ }^{\ddagger_{5}} \\
\$_{4}\end{array}$ & $\begin{array}{l}{ }^{\ddagger} D \\
{ }^{8} \mathrm{C}\end{array}$ & $9.2(1.3)$ & 88 \\
\hline 4 & $\begin{array}{l}\text { Treatment adherence should be discussed } \\
\text { and optimised within the process of } \\
\text { shared decision-making. }\end{array}$ & 5 & D & $9.5(1.0)$ & 97 \\
\hline 5 & $\begin{array}{l}\text { After failure of a second or subsequent } \\
\text { b/tsDMARD } \text { and particularly after }^{\S} \\
\text { two TNFi failures }{ }^{\S} \text { treatment with a b/ } \\
\text { tsDMARD with a different target should } \\
\text { be considered. }\end{array}$ & $\begin{array}{l}{ }^{\ddagger} 4 \\
\S_{3}\end{array}$ & $\begin{array}{l}{ }^{\ddagger} \mathrm{C} \\
{ }^{8} \mathrm{C}\end{array}$ & $9.2(1.3)$ & 94 \\
\hline 8 & $\begin{array}{l}\text { In patients with concomitant } \mathrm{HBV} / \mathrm{HCV} \\
\text { infection, b/tsDMARDs can be used }{ }^{\ddagger} \text { and } \\
\text { concomitant antiviral prophylaxis or } \\
\text { treatment should be considered in close } \\
\text { collaboration with the hepatologist }{ }^{\S} \text {. }\end{array}$ & $\begin{array}{l}{ }^{\ddagger} 4 \\
\S_{5}\end{array}$ & $\begin{array}{l}{ }^{\ddagger} C \\
{ }^{\S} \mathrm{D}\end{array}$ & $8.9(1.4)$ & 88 \\
\hline 9 & $\begin{array}{l}\text { In addition to pharmacological treatment, } \\
\text { non-pharmacological interventions (ie, } \\
\text { exercise }^{\ddagger}, \text { psychological }^{\S} \text {, educational } \\
\text { and self-management interventions }{ }^{\ddagger} \text { ) } \\
\text { should be considered to optimise } \\
\text { management of functional disability, } \\
\text { pain and fatigue. }\end{array}$ & $\begin{array}{l}\ddagger_{3} 3 \\
\S_{4}\end{array}$ & $\begin{array}{l}{ }^{\ddagger} \mathrm{C} \\
{ }^{8} \mathrm{C}\end{array}$ & $9.4(1.2)$ & 97 \\
\hline 10 & $\begin{array}{l}\text { Appropriate education and support } \\
\text { should be offered to patients to directly } \\
\text { inform their choices of treatment goals } \\
\text { and management. }\end{array}$ & 4 & C & $9.4(1.2)$ & 97 \\
\hline 11 & $\begin{array}{l}\text { Consider offering self-management } \\
\text { programmes, relevant education and } \\
\text { psychological interventions to optimise } \\
\text { patient's ability to manage their disease } \\
\text { confidently (ie, self-efficacy). }\end{array}$ & 3 & C & $9.1(1.7)$ & 91 \\
\hline
\end{tabular}


Table 1 Continued

LoE $^{22} \quad$ SoR $^{22} \quad$ LoA mean (SD) $\quad \geq 8 / 10(\%)$

In case the LoE and SoR differed for different items within a PtC, differences in LoE and SoR are shown using the symbols and §.

*Relevant mimicking diseases, for instance, crystal arthropathies, polymyalgia rheumatica, psoriatic arthritis, spondyloarthritis, Still's disease, SLE, Rhupus syndrome, vasculitis, idiopathic inflammatory myopathies, RS3PE, reactive arthritis (eg, parvo B19, Rubella, Whipple's disease, HBV and HCV infections), paraneoplastic syndromes, osteoarthritis and fibromyalgia.

tRelevant comorbidities: for instance, infections, malignancies, polymyalgia rheumatica and osteoarthritis, and consequences of longstanding destructive disease such as subluxations and joint dislocations.

b/tsDMARD, biological and targeted synthetic disease-modifying antirheumatic drugs; D2T, difficult-to-treat; EULAR, European Alliance of Associations for Rheumatology; HBV , hepatitis B virus; HCV, hepatitis C virus; LoA, levels of agreement; LoE, level of evidence (according to the standards of the Oxford Centre for Evidence-Based Medicine); NA, not applicable; PtCs, points to consider; RA, rheumatoid arthritis; RS3PE, remitting symmetric seronegative synovitis and pitting oedema; SLE, systemic lupus erythematosus; SoR, strengths of recommendations (according to the standards of the Oxford Centre for Evidence-Based Medicine); TNFi, tumour necrosis factor inhibitor; US, ultrasonography.

This suggests that US may be better related to 'true' inflammatory activity in these patients and may have additional value in patients with D2T RA in whom a doubt about the presence of inflammatory activity exists. However, the minimal number of joints that should be included in an US assessment remains unclear, ${ }^{41}$ which hampers the use of a sum score to determine the overall level of disease activity in daily practice. Of note, no studies were found on tests in patients with comorbidities that may influence the assessment of disease activity.

The evidence for biomarkers (eg, miR-146, fibrinogen, resistin, matrix metallopeptidase 3, interleukin 6 and multibiomarker disease activity score) and other imaging measures (eg, MRI or optical spectral transmission measures) is currently less convincing. ${ }^{20} 4047-61$ The quality of this evidence was low to moderate and no evidence could be identified on their role in patients in whom there was explicit doubt about the presence of inflammatory activity resulting in indirectness. These limitations hamper the current use of these biomarkers and imaging modalities in daily practice.

The Task Force unanimously agreed with this PtC $(100 \%$ agreed, first round, $\mathrm{n}=24$ ).

(3) Composite indices and clinical evaluation should be interpreted with caution in the presence of comorbiditiest, in particular obesity and fibromyalgia $a^{\S}$, as these may directly heighten

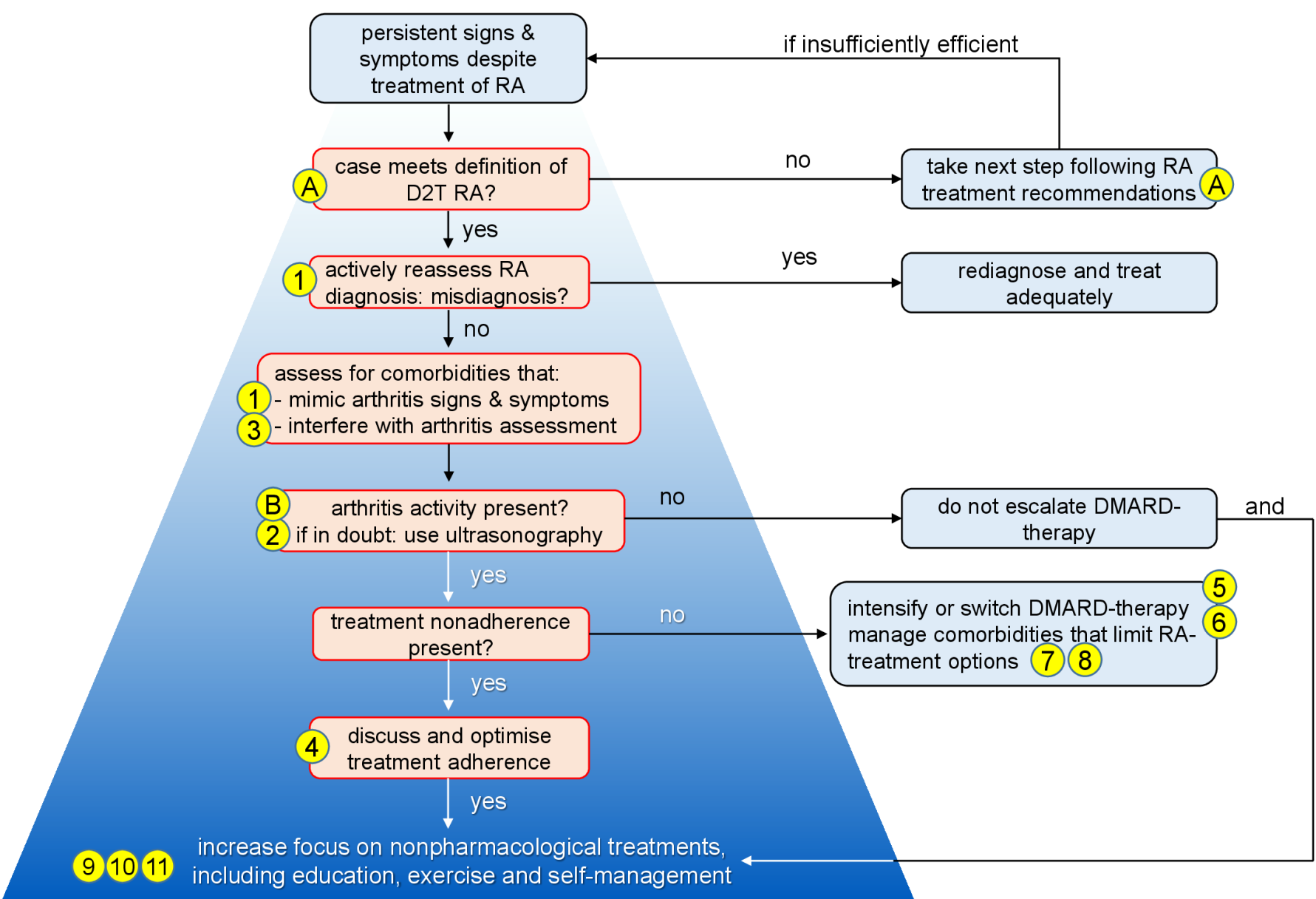

Figure 1 Algorithm based on the EULAR PtCs for the management of D2T RA. The pyramid background with increasing intensity of blue colour indicates non-pharmacological approaches and treatments, which are important throughout all phases of RA, but especially so if pharmacological treatment options are limited. The letters and numbers indicate the corresponding overarching principles and PtCs, respectively; see table 1. D2T, difficult-to-treat; DMARD, disease-modifying antirheumatic drug; EULAR, European Alliance of Associations for Rheumatology; PtCs, points to consider; RA, rheumatoid arthritis. 
inflammatory activity and/or overestimate disease activity ( $\neq$ LoE: 5, SoR: D; ${ }^{S} L o E$ : 4, SoR: C; LoA: 9.2 (1.3)).

Although the Task Force was unanimous in its opinion that numerous comorbidities might influence the assessment of inflammatory disease activity, substantial evidence was only found for obesity and fibromyalgia. ${ }^{2062-65}$ These two conditions may also frequently coexist, further complicating the precise assessment of inflammatory disease activity. Other comorbidities (especially those increasing acute phase reactants: eg, infections, malignancies or polymyalgia rheumatica) may lead to misclassification of inflammatory RA activity, although no substantial evidence was identified to support this. In addition, no evidence was identified regarding the impact of osteoarthritis, subluxation or joint dislocations on clinical evaluation of joints. ${ }^{20}$ It should be noted that the identification of synovitis and tenderness due to inflammation is generally more difficult in joints with destruction, since, for example, tenderness could be due to destruction rather than synovitis. The Task Force agreed that this PtC should refer to all potential comorbidities that may influence the evaluation of inflammatory disease activity. The Task Force unanimously agreed with this PtC (100\% agreed, first round, $\mathrm{n}=24)$.

(4) Treatment adherence should be discussed and optimised within the process of shared decision-making (LoE: 5, SoR: D, LoA: 9.5 (1.0)).

In RA, drug non-adherence rates reportedly vary between $30 \%$ and $80 \%{ }^{1866-68}$ and these rates are indicated to be substantially higher in patients with D2T RA compared with patients with non-D2T RA. ${ }^{26}$ Suboptimal adherence is associated with higher disease activity levels, which may result in inappropriate treatment switches and reduced quality of life. ${ }^{69-73}$ In a patient with D2T RA, this could exhaust all currently available (b/ts) DMARDs. Therefore, the Task Force unanimously agreed that adherence should be addressed as a standalone PtC. Another EULAR project has recently provided detailed PtCs for the detection, assessment and management of non-adherence in people with rheumatic and musculoskeletal diseases (RMDs). We, therefore, refer to their SLR and PtCs. ${ }^{18} 19$

The Task Force agreed to concur with WHO definitions ${ }^{74}$ and especially considered 'treatment adherence' instead of 'drug adherence', as the PtC also applies to non-pharmacological strategies. There is no gold standard for identifying non-adherence. Questionnaires or serum and/or urine drug level measurements may be used. ${ }^{187576}$ If suboptimal adherence is present, this might be explained by various factors; both unintentional (eg, forgetting to take the prescribed drugs) and intentional non-adherence (driven by a decision not to take the prescribed drugs, eg, due to fear of side effects) are common in RA. ${ }^{667677}$ The patient's evaluation of the risk-benefit ratio of the selected drug(s) is also of paramount importance. Therefore, discussions on adherence remain highly important. In addition to physicians, other HCPs, such as nurses experienced with patients with RA, psychologists and pharmacists, may also be involved in these discussions.

Shared decision-making is clearly vital to optimise adherence. ${ }^{1876}$ In this context, the quality of the relationship between the patient and the HCP is important. ${ }^{78} 79$ As non-adherence is a vulnerable topic, the patient should be made to feel safe and supported to discuss all aspects. In addition, appropriate education, especially in case of intentional non-adherence, would be useful and could strengthen the process of shared decisionmaking (see also PtCs $\$ 9$ and 10). ${ }^{18} 76$ This PtC was accepted in the first round of the voting process $(96 \%$ agreed, first round, $\mathrm{n}=28$ ).

(5) After failure of a second or subsequent b/tsDMARD $\neq$ and particularly after two tumour necrosis factor inhibitor (TNFi)

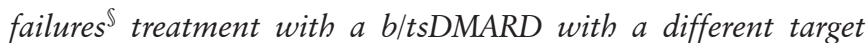
should be considered ( $\neq$ LoE: 4, SoR: C; ${ }^{\circledR}$ LoE: 3, SoR: C; LoA: $9.2(1.3))$.

Increasing numbers of $\mathrm{b} / \mathrm{tsDMARDs}$ (with different MOA) are available for the treatment of RA. ${ }^{80}$ Switching within class as well as switching to a drug with a different MOA can be effective. ${ }^{2080}$ However, a considerable proportion of patients with RA fail at least two b/tsDMARDs with different MOA, which may result in reaching criteria for D2T RA. ${ }^{12} 1381$ In routine practice, a trial-and-error approach to DMARD cycling predominates when signs and/or symptoms suggestive active disease are present. ${ }^{13}$ In the SLR, only limited evidence was identified on pharmacological therapeutic strategies in patients with RA in whom at least two b/tsDMARDs (specifically with different MOA) failed. ${ }^{21}$ Several identified trials in patients with RA in whom multiple b/tsDMARDs failed did not clearly state reasons for previous DMARD failure (eg, toxicity, lack of efficacy or other factors). This resulted in the inclusion of heterogeneous patient populations, complicating interpretation of outcomes.

After failure of at least two b/tsDMARDs, some evidence was identified regarding the beneficial effect of treatment with a b/tsDMARD with a different target. ${ }^{21}$ This evidence indicated that a third or fourth b/tsDMARD (ie, tocilizumab, tofacitinib, baricitinib, upadacitinib and filgotinib) is more effective than placebo. ${ }^{82-87}$ However, no preference can be given to any of these DMARDs. In patients with failure of at least one prior bDMARD, TNFi, abatacept and rituximab were more effective than placebo, ${ }^{8088-92}$ although direct evidence was lacking about the efficacy as third and fourth bDMARD compared with placebo. ${ }^{21}$ Where a higher number of prior bDMARDs had been ineffective, the extent of the beneficial effect of several $\mathrm{b} / \mathrm{tsDMARDs}$ (TNFi and the lower doses of tocilizumab, tofacitinib and baricitinib) was less. ${ }^{82} 8393-97$ Furthermore, a tendency was identified for non-TNFis to be more efficacious than TNFis in patients in whom at least one bDMARD failed (predominantly if TNFi was failed). ${ }^{88} 899598-115$ Our current PtC proposes to switch to a b/tsDMARD of different MOA, after failure of a second or subsequent b/tsDMARD and, particularly, after failure of two TNFis. This PtC was accepted in the first round of the voting process $(96 \%$ agreed, first round, $\mathrm{n}=24$ ).

The Task Force emphasised that the current $\mathrm{PtC}$ is in line with the 2019 EULAR RA recommendation on b/tsDMARD switches. Our $\mathrm{PtC}$ adds the following: first, there is value in prescribing another $b / t s D M A R D$ after failure of a second or subsequent $b$ / tsDMARD; and second, a b/tsDMARD with a different MOA is preferred after failure of a second or subsequent b/tsDMARD. ${ }^{2}$ Concerning DMARD combination therapy, we refer to the 2019 RA EULAR recommendations, as no additional evidence was identified for D2T RA. ${ }^{2}$

(6) If a third or subsequent b/tsDMARD is being considered, the maximum dose, as found effective and safe in appropriate testing, should be used (LoE: 3, SoR: C, LoA: 8.4 (1.8)).

The extent of the beneficial effect of $b / t s D M A R D s$ was generally less in patients in whom a higher number of previous bDMARDs failed. ${ }^{21}$ This tendency was not so apparent for upadacitinib and filgotinib, and for the higher doses of tocilizumab (intravenously administered, $8 \mathrm{mg} / \mathrm{kg}$ ), baricitinib (4 mg once daily) and tofacitinib (10 mg two times per day, although tofacitinib is not licensed at higher doses than $5 \mathrm{mg}$ two times per day because of safety concerns). ${ }^{828385879697}$ It should be noted, however, that baricitinib ( $4 \mathrm{mg}$ once daily) should not be used in patients older than 75 years or those with reduced creatinine clearance $(30-60 \mathrm{~mL} / \mathrm{min})$. 
This suggests that the higher doses of intravenous tocilizumab, and tofacitinib and baricitinib may be preferred in patients in whom previously a higher number of bDMARDs failed. ${ }^{82} 839697$ The evidence supports the use of higher doses from the beginning, excepting patients in whom contraindications for this higher dose are present.

In addition, it was argued that this $\mathrm{PtC}$ might be more informative by including the names of the specific $b / t s D M A R D$ (baricitinib and tocilizumab, and not tofacitinib, as tofacitinib is not licensed at higher doses than $5 \mathrm{mg}$ two times per day). The following wording was accepted $(95 \%$ agreed, first round, $n=22$ ): 'If a second or subsequent b/tsDMARD has failed, and baricitinib or iv tocilizumab are being considered, the higher licensed dose should be used if appropriate'. However, it was also discussed that explicitly mentioning drug names (ie, baricitinib and tocilizumab) should be avoided in management PtCs as novel evidence may emerge for other drugs. Therefore, the Steering Committee initiated a new voting after the Task Force meeting regarding this $\mathrm{PtC}$ without explicit drug names. The Task Force members agreed to change the wording of the $\mathrm{PtC}$ and to exclude the drug names resulting in the current recommendation (94\% agreed, second round, $\mathrm{n}=32$ ).

(7) Comorbidities that impact quality of life either independently or by limiting $R A$ treatment options, should be carefully considered and managed (LoE: 5, SoR: D, LoA: 9.3 (0.8)).

In clinical practice, comorbidities may significantly limit treatment options, potentially contributing to the D2T state. ${ }^{71315116}$ The Task Force agreed to formulate a $\mathrm{PtC}$ on the importance of comorbidities (100\% agreed, first round, $\mathrm{n}=28$ ).

We sought evidence about safe and efficacious therapies in patients with such contraindications. ${ }^{21}$ No studies were identified for patients with RA with HIV, gastrointestinal disease, latent tuberculosis and malignancies; only limited evidence was identified for patients with RA with extra-articular manifestations, hepatic disease, osteoporosis, psychological distress, pulmonary disease and renal disease. More than one study per intervention was identified only for patients with RA with HBV, $\mathrm{HCV}$ (see also PtC \#8), CVD, before and during pregnancy and lactation, and obesity.

Concerning venous thromboembolisms (VTEs), higher frequencies of VTEs were reported in patients with RA using tsDMARDs at high doses, and in whom risk factors for VTE are present. ${ }^{117}$ The Task Force unanimously agreed that in patients at risk for VTEs, tsDMARDs, specifically at high doses, should be used with caution and per drug label recommendations. As this item is covered in the 2019 EULAR RA management recommendations ${ }^{2}$ and as the increased risk of VTEs is not specific for patients with D2T RA, the Task Force unanimously decided not to include this item as a standalone $\mathrm{PtC}$ (no formal voting). Nevertheless, the increased risk of VTEs should be considered as factor limiting treatment options, particularly for patients with D2T RA with VTE risk factors.

Recommendations about safe DMARDs use before and during pregnancy and lactation are published as 2016 EULAR PtCs and as a 2020 ACR guideline. ${ }^{118}{ }^{119}$ Few additional studies were identified, subsequently on these papers ${ }^{21120-122}$; therefore, we refer to the existing guidance. ${ }^{118} 119$

Although obesity does not limit drug options per se, treatment efficacy might be different in obese patients. ${ }^{13}{ }^{123}$ Intravenously administered infliximab may be less effective in patients with a body mass index (BMI) above $30 \mathrm{~kg} / \mathrm{m}^{2}$ compared with those with a BMI below $30 \mathrm{~kg} / \mathrm{m}^{2} .124125$ The Task Force voted whether this issue should be a standalone PtC. The first vote did not clearly indicate the preference of the Task Force (formulate a separate $\mathrm{PtC}$ on this item 58\%, $\mathrm{n}=24$ ). Further discussion noted that evidence for several other comorbidities was lacking or very limited. Two studies of relevance had a high RoB. ${ }^{124} 125$ The repeat vote indicated not to formulate a separate $\mathrm{PtC}$ on this item (formulate a separate PtC on this item: 12\%, n=24).

Clinically meaningful contraindications of some therapies may result in limited treatment options, for example, tocilizumab in case of diverticulitis or janus kinase (JAK) inhibitors in case of repeated herpes zoster infections. ${ }^{117}$ However, no substantial clinical evidence was identified about safe and/or efficacious therapies for patients with these conditions ${ }^{21}$ and, therefore, no specific PtCs were formulated. A broad range of comorbidities and coexisting conditions were discussed at the Task Force meeting but are not explicitly part of the PtCs due to the lack of evidence. $^{21}$

(8) In patients with concomitant $\mathrm{HBV} / \mathrm{HCV}$ infection, b/ tsDMARDs can be used $\neq$ and concomitant antiviral prophylaxis or treatment should be considered in close collaboration with the hepatologist ${ }^{\S}$ ( $\neq$ LoE: 4, SoR: C, ${ }^{\mathbb{L}}$ LoA: 5; SoR: D, LoA: 8.9 (1.4)).

Substantial evidence was identified related to HBV and HCV infections prompting a standalone PtC. ${ }^{21}$ TNFi, abatacept and tocilizumab may be considered in patients with $\mathrm{HBV},{ }^{126-128}$ and TNFi in patients with HCV. ${ }^{129} 130$ Furthermore, no evidence was identified regarding other b/tsDMARDs, but this does not indicate that these $\mathrm{b} / \mathrm{tsDMARD}$ are unsafe to use. Therefore, the Task Force voted not to include specific b/tsDMARDs in the PtC $(83 \%$ agreed, $n=24)$. Furthermore, the Task Force agreed that concomitant antiviral prophylaxis should be considered, ${ }^{126}$ and that the treatment should be conducted in close collaboration with the hepatologist. The Task Force unanimously agreed with this $\mathrm{PtC}(100 \%$ agreed, first round, $\mathrm{n}=24)$. It should be noted that concomitant antiviral prophylaxis is appropriate for $\mathrm{HBV}$ infection in case of $\mathrm{HCV}$ infection, antiviral treatment is necessary.

(9) In addition to pharmacological treatment, nonpharmacological interventions (ie, exerciseł, psychological ${ }^{\S}$, educational ${ }^{\ddagger}$ and self-management interventionst) should be considered to optimise management of functional disability, pain and fatigue ( $\neq$ LoE: 3, SoR: C; ${ }^{\circledR}$ LoE: 4, SoR: C; LoA: 9.4 (1.2)).

A wide spectrum of factors may contribute to the persistence of signs and/or symptoms, although these are not always directly related to inflammation (eg, functional disability, pain and fatigue). ${ }^{1326}$ Individually tailored non-pharmacological interventions are also important components of the management of D2T RA. ${ }^{132126}$ The SLR focused on non-DMARD interventions to improve non-inflammatory complaints in patients with RA who do not clearly have active inflammatory disease. ${ }^{21}$ It is not always possible to disentangle inflammatory and non-inflammatory symptoms in clinical practice. Non-pharmacological interventions should also be considered in all patients with D2T RA ${ }^{26}$ and not only in those patients without inflammatory RA activity.

Evidence emerged regarding the beneficial effect of exercise, education, psychological and self-management interventions to improve pain, fatigue and functional disability in RA, while substantial evidence regarding the role of non-pharmacological interventions to improve quality of life was lacking. ${ }^{21}$ Benefit of exercise in RA is well established ${ }^{131}$ and was specifically found to improve physical functioning. A wide range of physical activities might be advised in accordance with the patients' status, for example, aerobic exercises, water-based dynamic exercises, muscle strengthening or hand exercises. ${ }^{132-144}$ Psychological interventions could be applied, specifically to reduce pain and fatigue, for example, cognitive behavioural therapy and interventions focusing on stress management. ${ }^{142}$ 145-149 Furthermore, 
patient education can assist patients in learning about their disease and management options (see also PtCs \#4, 9 and 10) ${ }^{10}$ and was specifically found to improve physical functioning. ${ }^{139}$ Education can be provided one on one, but also in group sessions promoting patients to learn from each other. Lastly, selfmanagement programmes can be applied. These programmes are typically a combination of different non-pharmacological interventions (eg, exercise and education) and were found to optimise the management of pain, fatigue and functional disability (see also PtCs \#9 and 10). ${ }^{136}$ 150-159

Ideally, a package of care (ie, multimodal treatment) should be considered in accordance with the patient's needs and preferences. This individually tailored multimodal treatment can be provided by different members of the rheumatology team (eg, rheumatologists, rehabilitation physicians, nurses experienced with patients with RA, physiotherapists, occupational therapists, psychologists, pharmacists and podiatrists). The Task Force unanimously agreed with this $\mathrm{PtC}(100 \%$ agreed, first round, $\mathrm{n}=29)$.

(10) Appropriate education and support should be offered to patients to directly inform their choices of treatment goals and management (LoE: 4, SoR: C, LoA: 9.4 (1.2)).

Setting treatment goals is central in the management of RA. In the current EULAR RA management recommendations, clinical remission or at least low disease activity is the ideal target with adjustment of therapeutic strategies if there is no improvement at 3 months or if the treatment target is not achieved at 6 months (recommendation \#3). ${ }^{2}$ These treatment targets may be unrealistic to achieve for patients with D2T RA, considering their disease history, accrued joint damage and other factors that may contribute to the D2T RA state, ${ }^{13}$ and lead to unnecessary DMARD switches. Accordingly, in D2T RA, treatment goals should be tailored to the individual patient.

Discordance in a given set target between the patient and HCP could negatively impact disease outcomes. ${ }^{13}$ The SLR did not find a diagnostic method to identify a mismatch in treatment goals (between HCP and patient with RA). ${ }^{21}$ Treatment goals should be discussed to be able to identify a mismatch in treatment goals and to optimise goal setting in shared decision-making.

Web-based education tools improve patients' knowledge and certainty in treatment decisions. ${ }^{21}{ }^{160-163}$ Such tools could be used in addition to providing information via usual discussions. As perceptions on treatment goals and management may change over time continuous education between patients and HCPs remains important. This $\mathrm{PtC}$ was accepted in the first round of the voting process $(89 \%$ agreed, first round, $\mathrm{n}=28)$.

(11) Consider offering self-management programmes, relevant education and psychological interventions to optimise patient's ability to manage their disease confidently (ie, self-efficacy; LoE: 3, SoR: C, LoA: 9.1 (1.7)).

Self-efficacy refers to patients' ability to control or manage various aspects of their disease and has a major role in the well-being of patients. ${ }^{164}$ Self-efficacy beliefs determine how individuals think, feel and act, and are an important aspect of self-management. People with low self-efficacy quickly give up their goals when faced with difficulties and are at higher risk of worse levels of pain, fatigue, depression, anxiety and stress. ${ }^{164-166}$ All this may contribute to the D2T RA state. ${ }^{1326}$ In contrast, a strong sense of self-efficacy improves human performance and well-being in several ways, promotes the accomplishment of challenging goals and supports commitment to them. ${ }^{164}$ Improved self-efficacy may not only improve disease outcomes such as mental well-being but may also improve many aspects of health behaviour, including treatment adherence and willingness to change lifestyle factors. Therefore, strengthening self-efficacy is specifically important in D2T RA.

The Arthritis Self-Efficacy Scale (ASES), a tool to measure perceived self-efficacy to cope with the disease, ${ }^{167}$ was found as the most reliable measure of self-efficacy. ${ }^{21} 168$ However, the ASES is perhaps too general to evaluate self-efficacy ${ }^{168}$ and cutoffs for suboptimal self-management are not well-validated, so a standalone $\mathrm{PtC}$ regarding its application was not pursued $(89 \%$ agreed, $n=27)$. There was consensus that the ASES may be used as a screening instrument and to assess the change in self-efficacy over time. The Task Force considered it challenging to clearly define what constituted a suboptimal level of self-efficacy and agreed that offering interventions to improve self-efficacy could be beneficial for all patients with D2T RA.

The SLR identified self-management programmes, educational interventions and psychological interventions to have a beneficial effect on self-efficacy. ${ }^{21}$ Some evidence suggested patients would like more education on disease processes. ${ }^{21} 169170$ Educational interventions, for example, individual education, a group education programme or education through a mobile app, specifically improved self-efficacy and RA knowledge. ${ }^{154} 155$ 171-175 Psychological interventions, for example, cognitive behavioural therapy or relaxation therapy, not only improve self-efficacy, but may also reduce symptoms related to anxiety and depression. ${ }^{148} 151176$ Self-management programmes (ie, typically a combination of different nonpharmacological interventions) were also found to be effective in improving self-efficacy. ${ }^{136} 143$ 151-153 155-158 177-181 In addition, mobile health applications may improve self-management. ${ }^{182}$

The Task Force thoroughly debated if these interventions should be offered to every patient (mandatory) or should be considered only (optional). The Task Force agreed that selfmanagement programmes should be optional (agreed 82\%, $\mathrm{n}=28$ ). If a patient wishes to improve their self-efficacy, a shared decision-making that captures the patient's status and preferences should decide the type of intervention. This $\mathrm{PtC}$ was accepted in the first round of the voting process $(96 \%$ agreed, first round, $n=28$ ).

\section{Research agenda}

The Task Force created a research agenda containing research questions that are considered most relevant to address (table 2).

\section{DISCUSSION}

The term 'D2T RA' has recently been defined to characterise a heterogeneous group of patients with RA with persistent signs and symptoms. ${ }^{8101226}$ While the typical patient with D2T RA is characterised by longstanding disease and structural damage in whom (b/ts)DMARDs have been ineffective (multidrug resistant or 'true refractory' RA), this only represents a subgroup of this heterogeneous patient population. Identification of all factors potentially contributing to D2T RA warrants a holistic management approach and is essential in order to tailor management strategies to the individual patient. D2T RA constitutes an area of unmet need, which motivated our Task Force to develop a roadmap for clinical decision-making by HCPs and patients laid out in the current PtCs on diagnostic challenges and pharmacological and non-pharmacological therapeutic strategies (summarised in figure 1).

The PtCs promote individually tailored treatment interventions by addressing specific aspects of $b / t s D M A R D$ selection (including in patients with comorbidities and coexisting conditions) and non-pharmacological interventions to improve 


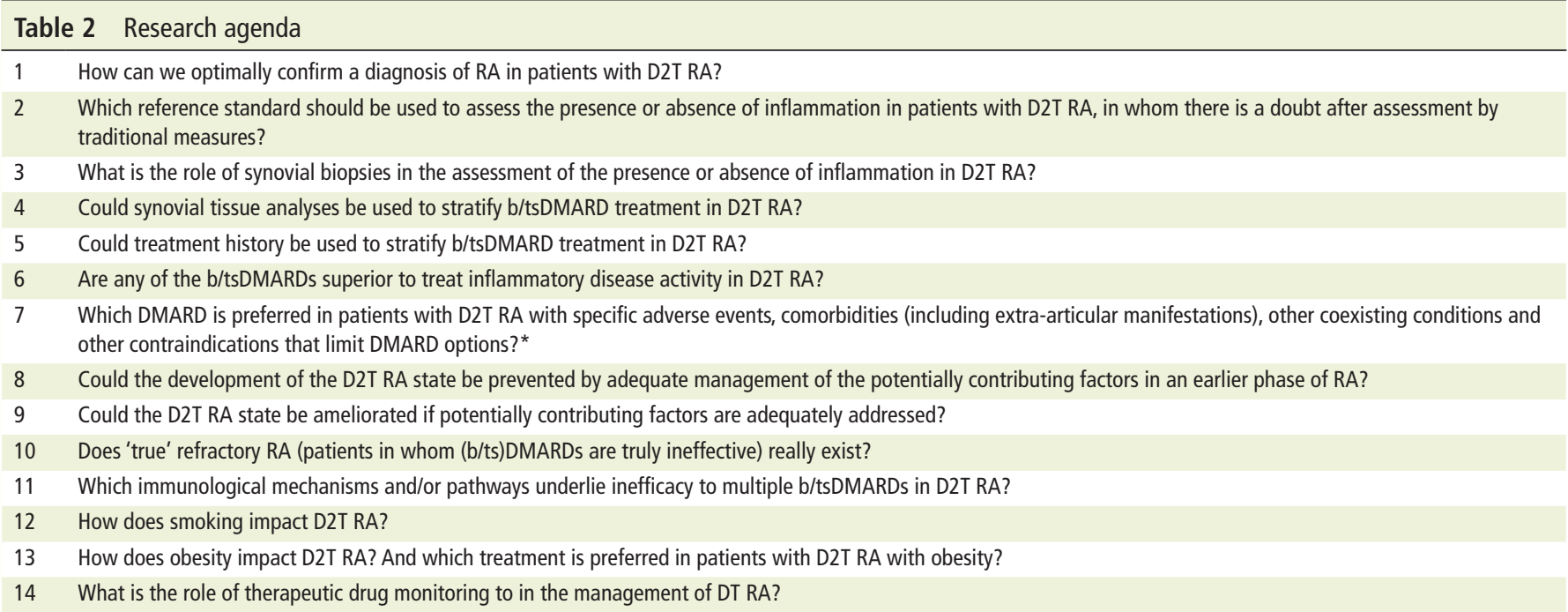

\begin{abstract}
*For example, infections (HIV and TB); malignancies; lung disease (fibrosis, asthma and COPD); CVD (hypertension and cardiomyopathy); hyperlipidaemia; chronic kidney dysfunction; chronic liver dysfunction; liver enzyme elevation; osteoporosis; diabetes mellitus; thrombosis; depression and anxiety. b/tsDMARDs, biological or targeted synthetic disease-modifying antirheumatic drugs; COPD, chronic obstructive pulmonary disease; CVD, cardiovascular disease; D2T, difficult-totreat; RA, rheumatoid arthritis; TB, tuberculosis.
\end{abstract}

adherence, functional disability, pain, fatigue, goal setting and self-efficacy. Although some of these PtCs may seem self-evident, our purpose in offering this $\mathrm{PtC}$ is to promote the need to address each of them in D2T RA management strategies. This approach mitigates against both overtreatment as well as undertreatment.

Although the Task Force aimed to cover all potential aspects of D2T RA, not all relevant topics were addressed in the SLRs because of overlap with previous or ongoing EULAR projects (eg, treatment non-adherence, lifestyle factors, pain syndromes and osteoarthritis, see below). Joint replacement and reconstructive surgery, both of which may have relevance in D2T RA, were not included in the systemic literature search, as these were considered out of scope. There was no substantial evidence identified regarding non-steroidal-anti-inflammatory drugs and analgesics in the context of D2T RA. ${ }^{21}$ For a few topics, the Task Force members considered a theme particularly relevant in the context of D2T RA as to merit highlighting herein. For instance, education is already addressed in separate EULAR recommendations ${ }^{10}$ but is crucial in the management of D2T RA ( $\$ 4$ and 9-11). Additionally, treatment non-adherence is common in patients with RMDs and may also contribute to the D2T RA state ${ }^{13267476}$; therefore, it has also been addressed in the D2T RA PtCs (\#4). Additional guidance on treatment non-adherence can be found in the recently published EULAR PtCs for the detection, assessment and management of non-adherence in people with RMDs. ${ }^{19}$

Furthermore, lifestyle factors, including diet, lack of exercise, smoking and alcohol consumption, might also be associated with D2T disease. ${ }^{13} 183$ Therefore, the management of lifestyle factors in patients with D2T RA was raised as a clinically relevant issue at our first Task Force meeting and resulted in the formulation of a research question on this topic. However, an ongoing EULAR project is focusing on lifestyle behaviour PtCs to prevent progression of RMDs and will be published soon. The Task Force, therefore, decided to refer to these PtCs for the management of these factors, as evidence in patients with D2T RA specifically was expected to be lacking.

Concomitant fibromyalgia and other pain syndromes as well as osteoarthritis may coexist in patients with D2T RA and may (partly) explain the persistence of signs and/or symptoms suggestive of active disease. ${ }^{1326}$ Because previous EULAR projects focused on these conditions, it was decided to refer to their recommendations. Guidance on the management of these coexisting conditions can be found in the 'EULAR revised recommendations for the management of fibromyalgia', ${ }^{23}$ 'EULAR recommendations for the health professional's approach to pain management in inflammatory arthritis and osteoarthritis, ${ }^{9}$ '2018 update of the EULAR recommendations for the management of hand osteoarthritis' ${ }^{24}$ and 'EULAR recommendations for the non-pharmacological core management of hip and knee osteoarthritis'. ${ }^{25}$

One of the main conclusions of the SLRs was the scarcity of high-quality direct evidence regarding D2T RA. ${ }^{20}{ }^{21}$ This is not surprising, considering the recent establishment of the EULAR definition of D2T RA. ${ }^{17}$ However, indirect evidence (ie, in patients with RA in whom at least two b/tsDMARDs failed, especially with different MOA) was also scarce and the quality was generally low to moderate. ${ }^{20} 21$ This lack of (high-quality) direct evidence can be seen as a limitation of these PtCs, but also as a stimulus for future studies to address patients with D2T RA specifically. Importantly, the heterogeneity of D2T RA should be considered when conducting such studies, as not all management strategies will be helpful in all patients with D2T RA. Selecting the appropriate patient population will, therefore, be crucial in order to obtain relevant results (see also table 2). As new evidence regarding D2T RA emerges, the PtCs on the management of D2T RA will need to be updated.

In summary, the evidence as identified in the SLRs together with expert opinion have resulted in a comprehensive set of overarching principles and PtCs for the management of D2T RA, promoting a holistic management approach and individually tailored pharmacological and non-pharmacological therapeutic strategies. Although high-quality evidence was scarce, these PtCs can be seen as a clinical roadmap and will provide assistance to HCPs and patients in the management of D2T RA. A research agenda was created to support future research in this emerging field.

\section{Author affiliations}

'Department of Rheumatology \& Clinical Immunology, Semmelweis University, Budapest, Hungary 
${ }^{2}$ Department of Genetics, Cell and Immunobiology, Semmelweis University, Budapest, Hungary

${ }^{3}$ Department of Rheumatology \& Clinical Immunology, University Medical Center Utrecht, Utrecht University, Utrecht, The Netherlands

${ }^{4}$ Bács-Kiskun County Hospital, Rheumatology Department, Kecskemét, Hungary

${ }^{5}$ Department of Rheumatology, Faculty of Medicine, University of Debrecen,

Debrecen, Hungary

${ }^{6}$ Department of Rheumatology, Meander Medical Center, Amersfoort, The Netherlands

${ }^{7}$ Salisbury Foundation Trust NHS Hospital, Wiltshire, UK

${ }^{8}$ EULAR Standing Committee of People with Arthritis/Rheumatism in Europe (PARE), Zurich, Switzerland

${ }^{9}$ Department of Rheumatology, 1st Faculty of Medicine, Charles University and Institute of Rheumatology, Prague, Czech Republic

${ }^{10}$ CREATE Centre, Section of Rheumatology, School of Medicine, Division of Infection and Immunity, Cardiff University, Cardiff, UK

${ }^{11}$ Université de Paris Department of Rheumatology - Hôpital Cochin. Assistance Publique - Hôpitaux de Paris INSERM (U1153) Clinical epidemiology and biostatistics, PRES Sorbonne Paris-Cité, Paris, France

${ }^{12}$ Department of Psychology, Utrecht University, Utrecht, The Netherlands

${ }^{13}$ Epidemiology Unit, German Rheumatism Research Centre, Berlin, Germany

${ }^{14}$ Department of Internal Medicine III, Division of Rheumatology, Medical University of Vienna, Vienna, Austria

${ }^{15}$ Department of Rheumatology, Bravis Hospital, Roosendaal, The Netherlands

${ }^{16}$ Department of Rheumatic Diseases, Radboud University Nijmegen Medical Centre, Nijmegen, The Netherlands

${ }^{17}$ Department of Pharmacy, Marin Hospital, Asisstance Publique-Hopitaux de Paris, Hendaye, France

${ }^{18}$ School of Health and Society, Centre for Health Sciences Research, University of Salford, Salford, UK

${ }^{19}$ Centre for Rheumatic Diseases, King's College London, London, UK

${ }^{20}$ Rheumatology Department, King's College Hospital, London, UK

${ }^{21}$ School of Medicine, Catholic University of the Sacred Heart, Rome, Italy

${ }^{22}$ Department of Internal Medicine 3, Rheumatology and Immunology, FriedrichAlexander University of Erlangen-Nuremberg and Universitatsklinikum Erlangen, Erlangen, Germany

${ }^{23} \mathrm{NIHR}$ Manchester Biomedical Research Centre, Manchester University NHS Foundation Trust, Manchester Academic Health Science Centre, Manchester, UK ${ }^{24}$ Centre for Musculoskeletal Research, School of Biological Sciences, Faculty of Biology, Medicine \& Health, University of Manchester, Manchester, UK

${ }^{25}$ Department of Rheumatology and Clinical Immunology, Justus-Liebig University Giessen, Campus Kerckhoff, Bad Nauheim, Germany

${ }^{26}$ Leeds Institute of Rheumatic \& Musculoskeletal Medicine, University of Leeds, Leeds, UK

${ }^{27}$ Institute of Infection, Immunity and Inflammation, University of Glasgow, Glasgow, UK

${ }^{28}$ Department of Rheumatology, Leiden University Medical Center, Leiden, The Netherlands

Twitter Yeliz Prior @YelizPrior and Elena Nikiphorou @ElenaNikiUK

Acknowledgements The Task Force is grateful for the support of EULAR and for the outstanding assistance of the EULAR Secretariat, especially Julia Rautenstrauch, Patrizia Jud and Simona Lupatin. The Task Force acknowledges the contribution of Maria J H de Hair (rheumatology postdoctoral fellow) and Loriane Gutermann (pharmacist), who left the Task Force due to their new positions.

Contributors GN and NMTR wrote the first draft of the manuscript, with the help from PMJW, DvdH and JMvL. All authors participated in the work of the Task Force, provided co-author contribution to the manuscript and read and approved the final manuscript.

Funding This project was funded by European Alliance of Associations for Rheumatology.

Competing interests Participants provided declaration of interest, the individual declarations will be attached as online supplemental file.

Patient and public involvement Patients and/or the public were involved in the design, or conduct, or reporting, or dissemination plans of this research. Refer to the Methods section for further details.

Patient consent for publication Not required.

Provenance and peer review Not commissioned; externally peer reviewed.

Open access This is an open access article distributed in accordance with the Creative Commons Attribution Non Commercial (CC BY-NC 4.0) license, which permits others to distribute, remix, adapt, build upon this work non-commercially, and license their derivative works on different terms, provided the original work is properly cited, appropriate credit is given, any changes made indicated, and the use is non-commercial. See: http://creativecommons.org/licenses/by-nc/4.0/.

\section{ORCID iDs}

György Nagy http://orcid.org/0000-0003-1198-3228

Nadia M T Roodenrijs http://orcid.org/0000-0002-4364-3183

Melinda Kedves http://orcid.org/0000-0002-9271-5024

Attila Hamar http://orcid.org/0000-0002-3399-4801

Zoltan Szekanecz http://orcid.org/0000-0002-7794-6844

Ernest H Choy http://orcid.org/0000-0003-4459-8609

Johannes WG Jacobs http://orcid.org/0000-0002-7438-3468

Johannes WJ Bijlsma http://orcid.org/0000-0002-0128-8451

Daniel Aletaha http://orcid.org/0000-0003-2108-0030

Yeliz Prior http://orcid.org/0000-0001-9831-6254

Elena Nikiphorou http://orcid.org/0000-0001-6847-3726

Gianfranco Ferraccioli http://orcid.org/0000-0002-6884-4301

Georg Schett http://orcid.org/0000-0001-8740-9615

Kimme L Hyrich http://orcid.org/0000-0001-8242-9262

Maya H Buch http://orcid.org/0000-0002-0833-4852

Désirée van der Heijde http://orcid.org/0000-0002-5781-158X

Jacob M van Laar http://orcid.org/0000-0001-5544-5785

\section{REFERENCES}

1 Smolen JS, Aletaha D, McInnes IB. Rheumatoid arthritis. Lancet 2016:388:2023-38.

2 Smolen JS, Landewé RBM, Bijlsma JWJ, et al. EULAR recommendations for the management of rheumatoid arthritis with synthetic and biological disease-modifying antirheumatic drugs: 2019 update. Ann Rheum Dis 2020;79:685-99.

3 Singh JA, Saag KG, Bridges SL. American College of rheumatology guideline for the treatment of rheumatoid arthritis. Arthritis Rheumatol 2015;2016:1-26.

4 Brenol CV, Nava JIG, Soriano ER. Proper management of rheumatoid arthritis in Latin America. what the guidelines say? Clin Rheumatol 2015;34:51-5.

5 Lau CS, Chia F, Dans L, et al. 2018 update of the APLAR recommendations for treatment of rheumatoid arthritis. Int I Rheum Dis 2019:22:357-75.

6 Agca R, Heslinga SC, Rollefstad S, et al. EULAR recommendations for cardiovascular disease risk management in patients with rheumatoid arthritis and other forms of inflammatory joint disorders: 2015/2016 update. Ann Rheum Dis 2017;76:17-28.

7 Baillet A, Gossec L, Carmona L, et al. Points to consider for reporting, screening for and preventing selected comorbidities in chronic inflammatory rheumatic diseases in daily practice: a EULAR initiative. Ann Rheum Dis 2016;75:965-73.

8 Colebatch AN, Edwards CJ, Østergaard M, et al. EULAR recommendations for the use of imaging of the joints in the clinical management of rheumatoid arthritis. Ann Rheum Dis 2013;72:804-14.

9 Geenen R, Overman CL, Christensen R, et al. EULAR recommendations for the health professional's approach to pain management in inflammatory arthritis and osteoarthritis. Ann Rheum Dis 2018:77:797-807.

10 Zangi HA, Ndosi M, Adams J, et al. EULAR recommendations for patient education for people with inflammatory arthritis. Ann Rheum Dis 2015;74:954-62.

11 Smolen JS, Breedveld FC, Burmester GR, et al. Treating rheumatoid arthritis to target: 2014 update of the recommendations of an international Task force. Ann Rheum Dis 2016;75:3-15.

12 Buch MH. Defining refractory rheumatoid arthritis. Ann Rheum Dis 2018;77:966-9.

13 de Hair MJH, Jacobs JWG, Schoneveld JLM. Difficult-To-Treat rheumatoid arthritis: an area of unmet clinical need. Rheumatology 2017;57:1135-44.

14 Buch MH, Eyre S, McGonagle D. Persistent inflammatory and non-inflammatory mechanisms in refractory rheumatoid arthritis. Nat Rev Rheumatol 2021;17:17-33.

15 Roodenriis NMT, de Hair MJH, van der Goes MC, et al. Characteristics of difficultto-treat rheumatoid arthritis: results of an international survey. Ann Rheum Dis 2018:77:1705-9

16 van der Heijde D, Aletaha D, Carmona L, et al. 2014 update of the EULAR standardised operating procedures for EULAR-endorsed recommendations. Ann Rheum Dis 2015;74:8-13.

17 Nagy G, Roodenrijs NM, Welsing PM, et al. EULAR definition of difficult-to-treat rheumatoid arthritis. Ann Rheum Dis 2021:80:31-5.

18 Ritschl V, Stamm TA, Aletaha D, et al. Prevention, screening, assessing and managing of non-adherent behaviour in people with rheumatic and musculoskeletal diseases: systematic reviews Informing the 2020 EULAR points to consider. RMD Open 2020:6:e001432.

19 Ritschl V, Stamm TA, Aletaha D, et al. 2020 EULAR points to consider for the prevention, screening, assessment and management of non-adherence to treatment in people with rheumatic and musculoskeletal diseases for use in clinical practice. Ann Rheum Dis 2020:annrheumdis-2020-218986.

20 Roodenrijs NMT, Kedves M, Hamar A, et al. Diagnostic issues in difficult-totreat rheumatoid arthritis: a systematic literature review Informing the EULAR recommendations for the management of difficult-to-treat rheumatoid arthritis. RMD Open 2021;7:e001511.

21 Roodenrijs NMT, Hamar A, Kedves M, et al. Pharmacological and nonpharmacological therapeutic strategies in difficult-to-treat rheumatoid arthritis: 
a systematic literature review Informing the EULAR recommendations for the management of difficult-to-treat rheumatoid arthritis. RMD Open 2021;7:e001512.

22 OCEBM Levels of Evidence Working Group, Oxford Centre for Evidence-Based Medicine. The Oxford 2011 levels of evidence, 2011. Available: https://www.cebm. net/2016/05/ocebm-levels-of-evidence/

23 Macfarlane GJ, Kronisch C, Dean LE, et al. EULAR revised recommendations for the management of fibromyalgia. Ann Rheum Dis 2017;76:318-28.

24 Kloppenburg M, Kroon FPB, Blanco FJ. Update of the EULAR recommendations for the management of hand osteoarthritis. Ann Rheum Dis 2018;2019:16-24.

25 Fernandes L, Hagen KB, Bijlsma JWJ, et al. EULAR recommendations for the nonpharmacological core management of hip and knee osteoarthritis. Ann Rheum Dis 2013:72:1125-35.

26 Roodenrijs NMT, van der Goes MC, Welsing PMJ, et al. Difficult-To-Treat rheumatoid arthritis: contributing factors and burden of disease. Rheumatology 2020:keaa860.

27 Pedersen JK, Lorenzen T, Ejbjerg B, et al. Low-Field magnetic resonance imaging or combined ultrasonography and anti-cyclic citrullinated peptide antibody improve correct classification of individuals as established rheumatoid arthritis: results of a population-based, cross-sectional study. BMC Musculoskelet Disord 2014;15:268.

28 Fan A, Tournadre A, Pereira B, et al. Performance of fibromyalgia rapid screening tool (first) to detect fibromyalgia syndrome in rheumatic diseases. Rheumatology 2016;55:1746-50.

29 Ghib LJ, Cojocneanu-Petric R, Budisan L. THU0518 the diagnostic value of selected microRNAs in patients with fibromyalgia associated with rheumatoid arthritis: a pilot study. Ann Rheum Dis 2018;77:463.3-4.

30 Salaffi F, Di Carlo M, Carotti M, et al. The subjective components of the disease activity score 28-joints (DAS28) in rheumatoid arthritis patients and coexisting fibromyalgia. Rheumatol Int 2018;38:1911-8.

31 Sato H, Tanabe N, Murasawa A, et al. Procalcitonin is a specific marker for detecting bacterial infection in patients with rheumatoid arthritis. J Rheumatol 2012:39:1517-23.

32 Paalanen K, Puolakka K, Nikiphorou E. Is seronegative rheumatoid arthritis true rheumatoid arthritis? A nationwide cohort study. Rheumatology 2021;60:keaa623-2395.

33 Nikiphorou E, Sjöwall C, Hannonen P, et al. Long-term outcomes of destructive seronegative (rheumatoid) arthritis - description of four clinical cases. BMC Musculoskelet Disord 2016;17:246.

34 Aletaha D, Neogi T, Silman AJ. Rheumatoid arthritis classification criteria: an American College of Rheumatology/European League against rheumatism collaborative initiative. Ann Rheum Dis 2010;2010:1580-8.

35 Burgers LE, Raza K, van der Helm-van Mil AH. Window of opportunity in rheumatoid arthritis - definitions and supporting evidence: from old to new perspectives. RMD Open 2019;5:V

36 Landewé RBM. Overdiagnosis and overtreatment in rheumatology: a little caution is in order. Ann Rheum Dis 2018:77:1394-6.

37 Jacobs JWG, van Rijthoven AWAM. [Diagnostic image (290). A woman with painful finger joints and swelling]. Ned Tijdschr Geneeskd 2006;150:1982.

38 Ceponis A, Onishi M, Bluestein HG, et al. Utility of the ultrasound examination of the hand and wrist joints in the management of established rheumatoid arthritis. Arthritis Care Res 2014;66:236-44.

39 Filer A, Mandelin Al, DiCarlo E. Histological and Clinical Correlates of Ultrasound Measures of Joint Inflammation: Analysis of RA Tissue Obtained By Ultrasound Guided Biopsy in Phase 1 of the Accelerating Medicines Partnership RA Network [abstract]. Arthritis Rheumatol 2017;69 https://acrabstracts.org/abstract/histologicaland-clinical-correlates-ofultrasound-measures-of-joint-inflammation-analysis-ofra-tissue-obtained-by-ultrasoundguided-biopsy-in-phase-1-of-the-acceleratingmedicines-partnership-ra-ne/

40 Kawashiri S-ya, Kawakami A, Iwamoto N, et al. The power Doppler ultrasonography score from 24 synovial sites or 6 simplified synovial sites, including the metacarpophalangeal joints, reflects the clinical disease activity and level of serum biomarkers in patients with rheumatoid arthritis. Rheumatology 2011;50:962-5.

41 Mandl P, Naredo E, Wakefield RJ, et al. A systematic literature review analysis of ultrasound joint count and scoring systems to assess synovitis in rheumatoid arthritis according to the OMERACT filter. J Rheumatol 2011;38:2055-62.

42 Yokota K, Tsuzuki Wada T, Akiyama Y, et al. Detection of synovial inflammation in rheumatic diseases using superb microvascular imaging: comparison with conventional power Doppler imaging. Mod Rheumatol 2018:28:327-33.

43 Vlad V, Berghea F, Libianu S, et al. Ultrasound in rheumatoid arthritis: volar versus dorsal synovitis evaluation and scoring. BMC Musculoskelet Disord 2011:12:124.

44 Ngai Ng S, Bjørndal Axelsen M, Ostergaard M. OP0135 how well does whole body magnetic resonance imaging agree with whole body ultrasound in the assessment of joint inflammation in rheumatoid arthritis patients. Ann Rheum Dis 2019;78:143.

45 Takase-Minegishi K, Horita N, Kobayashi K, et al. Diagnostic test accuracy of ultrasound for synovitis in rheumatoid arthritis: systematic review and meta-analysis. Rheumatology 2018;57:49-58.

46 Ciurtin C, Brown G, Cotton A. THU0138 Das 28 correlated poorly with the objective evidence of inflammation as detected by ultrasound (US) examination of hands and feet in patients with established rheumatoid arthritis $(\mathrm{rA})$. Ann Rheum Dis 2017;76:253.1-253.
47 Senolt L, Housa D, Vernerová Z, et al. Resistin in rheumatoid arthritis synovial tissue, synovial fluid and serum. Ann Rheum Dis 2007:66:458-63.

48 Skacelova M, Hermanova Z, Horak P, et al. Higher levels of matrix metalloproteinase-3 in patients with RA reflect disease activity and structural damage. Biomed Pap Med Fac Univ Palacky Olomouc Czech Repub 2017:161:296-302.

49 Tuncer T, Kaya A, Gulkesen A, et al. Matrix metalloproteinase-3 levels in relation to disease activity and radiological progression in rheumatoid arthritis. Adv Clin Exp Med 2019;28:665-70.

50 Yildirim K, Karatay S, Melikoglu MA. Associations between acute phase reactant levels and disease activity score (DAS28) in patients with rheumatoid arthritis. Ann Clin Lab Sci 2004:34:423-6.

51 van Onna M, Ten Cate DF, Tsoi KL, et al. Assessment of disease activity in patients with rheumatoid arthritis using optical spectral transmission measurements, a noninvasive imaging technique. Ann Rheum Dis 2016;75:511-8.

52 Meier AJL, Rensen WHJ, de Bokx PK, et al. Potential of optical spectral transmission measurements for joint inflammation measurements in rheumatoid arthritis patients. J Biomed Opt 2012;17:081420.

53 Besselink NJ, van der Meijde P, Rensen WHJ, et al. Optical spectral transmission to assess inflammation in hand and wrist joints of rheumatoid arthritis patients. Rheumatology 2018;57:865-72.

54 Bae S-C, Lee YH. Mir-146A levels in rheumatoid arthritis and their correlation with disease activity: a meta-analysis. Int I Rheum Dis 2018:21:1335-42.

55 Bustos Rivera-Bahena C, Xibillé-Friedmann D-X, González-Christen J, et al. Peripheral blood leptin and resistin levels as clinical activity biomarkers in Mexican rheumatoid arthritis patients. Reumatol Clin 2016;12:323-6.

56 do Prado AD, Bisi MC, Piovesan DM, et al. Ultrasound power Doppler synovitis is associated with plasma IL-6 in established rheumatoid arthritis. Cytokine 2016:83:27-32.

57 Johnson TM, Register KA, Schmidt CM, et al. Correlation of the Multi-Biomarker disease activity score with rheumatoid arthritis disease activity measures: a systematic review and Meta-Analysis. Arthritis Care Res 2019;71:1459-72.

58 Milman N, Karsh J, Booth RA. Correlation of a multi-cytokine panel with clinical disease activity in patients with rheumatoid arthritis. Clin Biochem 2010:43:1309-14.

59 Nordal HH, Brokstad KA, Solheim M, et al. Calprotectin (S100A8/A9) has the strongest association with ultrasound-detected synovitis and predicts response to biologic treatment: results from a longitudinal study of patients with established rheumatoid arthritis. Arthritis Res Ther 2017;19:3.

60 Roodenrijs NMT, de Hair MJH, Wheater G, et al. The multi-biomarker disease activity score tracks response to rituximab treatment in rheumatoid arthritis patients: a post hoc analysis of three cohort studies. Arthritis Res Ther 2018:20:256

61 Rooney T, Scherzer R, Shigenaga JK, et al. Levels of plasma fibrinogen are elevated in well-controlled rheumatoid arthritis. Rheumatology 2011;50:1458-65.

62 Bauer EM, Ben-Artzi A, Duffy EL, et al. Joint-specific assessment of swelling and power Doppler in obese rheumatoid arthritis patients. BMC Musculoskelet Disord 2017:18:99.

63 Sosa J, Karina Perez S, Julia Santa Cruz M. M-DAS28, M-SDAI and M-CDAI Performance in a Cohort of RA Patients with and without Concomitant Fibromyalgia [abstract]. Arthritis Rheumatol 2017;69 https://acrabstracts.org/abstract/m-das28m-sdai-andm-cdai-performance-in-a-cohort-of-ra-patients-with-and-withoutconcomitant-fibromyalgia

64 Ranganath VK, Duffy EL, Garg VK, et al. Obesity impacts swelling of ankle and foot joints in early rheumatoid arthritis patients. J Clin Rheumatol 2019;25:e8-11.

65 Goossens J, Coustet B, Palazzo E. Overweight and obesity affect clinical assessment of synovitis in rheumatoid arthritis: comparison of ultrasonography and clinical exam. Clin Exp Rheumatol 2019;37:49-54.

66 van den Bemt BJF, Zwikker HE, van den Ende CHM. Medication adherence in patients with rheumatoid arthritis: a critical appraisal of the existing literature. Expert Rev Clin Immunol 2012;8:337-51

67 Murage MJ, Tongbram V, Feldman SR, et al. Medication adherence and persistence in patients with rheumatoid arthritis, psoriasis, and psoriatic arthritis: a systematic literature review. Patient Prefer Adherence 2018;12:1483-503.

68 López-Medina C, Moltó A, Gérald F, et al. Assessment of the adherence to diseasemodifying drugs in patients with chronic inflammatory rheumatic diseases: results of a survey of 1594 patients. Joint Bone Spine 2019;86:610-4.

69 Contreras-Yáñez I, Ponce De León S, Cabiedes J, et al. Inadequate therapy behavior is associated to disease flares in patients with rheumatoid arthritis who have achieved remission with disease-modifying antirheumatic drugs. Am J Med Sci 2010:340:282-90

70 De Vera MA, Mailman J, Gao JS. Economics of non-adherence to biologic therapies in rheumatoid arthritis topical collection on health economics and quality of life. Curr Rheumatol Rep 2014:16:460.

71 Salaffi F, Carotti M, Di Carlo M, et al. Adherence to anti-tumor necrosis factor therapy administered subcutaneously and associated factors in patients with rheumatoid arthritis. J Clin Rheumatol 2015;21:419-25. 
72 Pasma A, Schenk CV, Timman R, et al. Non-adherence to disease-modifying antirheumatic drugs is associated with higher disease activity in early arthritis patients in the first year of the disease. Arthritis Res Ther 2015;17:281.

73 Pasma A, Schenk C, Timman R, et al. Does non-adherence to DMARDs influence hospital-related healthcare costs for early arthritis in the first year of treatment? PLoS One 2017;12:e0171070.

74 Sabaté E. WHO | adherence to long-term therapies: evidence for action. Geneva: World Health Organization, 2015.

75 Lam WY, Fresco P. Medication adherence measures: an overview. Biomed Res Int 2015;2015:1-12

76 Gossec L, Molto A, Romand X, et al. Recommendations for the assessment and optimization of adherence to disease-modifying drugs in chronic inflammatory rheumatic diseases: a process based on literature reviews and expert consensus. Joint Bone Spine 2019;86:13-19.

77 Joplin S, van der Zwan R, Joshua F, et al. Medication adherence in patients with rheumatoid arthritis: the effect of patient education, health literacy, and musculoskeletal ultrasound. Biomed Res Int 2015;2015:150658.

78 Makoul G, Clayman ML. An integrative model of shared decision making in medical encounters. Patient Educ Couns 2006:60:301-12

79 Dy SM, Purnell TS. Key concepts relevant to quality of complex and shared decisionmaking in health care: a literature review. Soc Sci Med 2012;74:582-7.

80 Kerschbaumer A, Sepriano A, Smolen JS, et al. Efficacy of pharmacological treatment in rheumatoid arthritis: a systematic literature research Informing the 2019 update of the EULAR recommendations for management of rheumatoid arthritis. Ann Rheum Dis 2020;79:744-59.

81 Kearsley-Fleet L, Davies R, De Cock D, et al. Biologic refractory disease in rheumatoid arthritis: results from the British Society for rheumatology biologics register for rheumatoid arthritis. Ann Rheum Dis 2018;77:1405-12.

82 Emery P, Keystone E, Tony HP, et al. II-6 receptor inhibition with tocilizumab improves treatment outcomes in patients with rheumatoid arthritis refractory to anti-tumour necrosis factor biologicals: results from a 24-week multicentre randomised placebocontrolled trial. Ann Rheum Dis 2008;67:1516-23.

83 Burmester GR, Blanco R, Charles-Schoeman C, et al. Tofacitinib (CP-690,550) in combination with methotrexate in patients with active rheumatoid arthritis with an inadequate response to tumour necrosis factor inhibitors: a randomised phase 3 trial. Lancet 2013;381:451-60.

84 Genovese MC, Fleischmann RM, Greenwald M, et al. Tabalumab, an anti-BAFF monoclonal antibody, in patients with active rheumatoid arthritis with an inadequate response to TNF inhibitors. Ann Rheum Dis 2013;72:1461-8.

85 Genovese MC, Kalunian K, Gottenberg J-E, et al. Effect of Filgotinib vs placebo on clinical response in patients with moderate to severe rheumatoid arthritis refractory to disease-modifying antirheumatic drug therapy: the finch 2 randomized clinical trial. JAMA 2019:322:315-25.

86 Kremer JM, Emery P, Camp HS, et al. A phase Ilb study of ABT-494, a selective JAK-1 inhibitor, in patients with rheumatoid arthritis and an inadequate response to antitumor necrosis factor therapy. Arthritis Rheumatol 2016;68:2867-77.

87 Weinblatt M, Thomson G, Chen K. FRI0171 clinical responses in patients with inadequate response to bdmards upon treatment with upadacitinib. Ann Rheum Dis 2019;78:759

88 Alivernini S, Laria A, Gremese E, et al. ACR70-disease activity score remission achievement from switches between all the available biological agents in rheumatoid arthritis: a systematic review of the literature. Arthritis Res Ther 2009;11:R163.

89 Kim H-L, Lee M-Y, Park S-Y, et al. Comparative effectiveness of cycling of tumor necrosis factor- $\alpha$ (TNF- $\alpha$ ) inhibitors versus switching to non-TNF biologics in rheumatoid arthritis patients with inadequate response to TNF- $\alpha$ inhibitor using a Bayesian approach. Arch Pharm Res 2014;37:662-70.

90 Lee YH, Bae S-C. Comparative efficacy and safety of tocilizumab, rituximab, abatacept and tofacitinib in patients with active rheumatoid arthritis that inadequately responds to tumor necrosis factor inhibitors: a Bayesian network metaanalysis of randomized controlled trials. Int J Rheum Dis 2016;19:1103-11.

91 Malottki K, Barton P, Tsourapas A, et al. Adalimumab, etanercept, infliximab, rituximab and abatacept for the treatment of rheumatoid arthritis after the failure of a tumour necrosis factor inhibitor: a systematic review and economic evaluation. Health Technol Assess 2011;15:1-300.

92 Singh JA, Hossain A, Tanjong Ghogomu E, et al. Biologics or tofacitinib for people with rheumatoid arthritis unsuccessfully treated with biologics: a systematic review and network meta-analysis. Cochrane Database Syst Rev 2017;2017.

93 Smolen JS, Kay J, Matteson EL, et al. Insights into the efficacy of golimumab plus methotrexate in patients with active rheumatoid arthritis who discontinued prior anti-tumour necrosis factor therapy: post-hoc analyses from the GO-AFTER study. Ann Rheum Dis 2014;73:1811-8.

94 Schiff M, Pritchard C, Huffstutter JE, et al. The 6-month safety and efficacy of abatacept in patients with rheumatoid arthritis who underwent a washout afte anti-tumour necrosis factor therapy or were directly switched to abatacept: the ARRIVE trial. Ann Rheum Dis 2009;68:1708-14.

95 Harrold LR, Reed GW, Magner R, et al. Comparative effectiveness and safety of rituximab versus subsequent anti-tumor necrosis factor therapy in patients with rheumatoid arthritis with prior exposure to anti-tumor necrosis factor therapies in the United States Corrona registry. Arthritis Res Ther 2015;17:256

96 Charles-Schoeman C, Kremer J, Krishnaswami S. THU0185 comparison of tofacitinib safety and efficacy in rheumatoid arthritis patients with inadequate response to conventional synthetic dmards, or to one or more biological dmards. Ann Rheum Dis 2017:76:271.3-2.

97 Genovese MC, Kremer JM, Kartman CE, et al. Response to baricitinib based on prior biologic use in patients with refractory rheumatoid arthritis. Rheumatology 2018;57:900-8

98 Chatzidionysiou K, van Vollenhoven RF. Rituximab versus anti-TNF in patients who previously failed one TNF inhibitor in an observational cohort. Scand J Rheumatol 2013:42:190-5.

99 Emery P, Gottenberg JE, Rubbert-Roth A, et al. Rituximab versus an alternative TNF inhibitor in patients with rheumatoid arthritis who failed to respond to a single previous TNF inhibitor: SWITCH-RA, a global, observational, comparative effectiveness study. Ann Rheum Dis 2015;74:979-84.

100 Gomez-Reino JJ, Maneiro JR, Ruiz J, et al. Comparative effectiveness of switching to alternative tumour necrosis factor (TNF) antagonists versus switching to rituximab in patients with rheumatoid arthritis who failed previous TNF antagonists: the MIRAR study. Ann Rheum Dis 2012;71:1861-4.

101 Kekow J, Mueller-Ladner U, Schulze-Koops H. Rituximab is more effective than second anti-TNF therapy in rheumatoid arthritis patients and previous TNF $\alpha$ blocker failure. Biol Targets Ther 2012;6:191-9.

102 Soliman MM, Hyrich KL, Lunt $\mathrm{M}$, et al. Rituximab or a second anti-tumor necrosis factor therapy for rheumatoid arthritis patients who have failed their first antitumor necrosis factor therapy? comparative analysis from the British Society for rheumatology biologics register. Arthritis Care Res 2012;64:1108-15.

103 Torrente-Segarra V, Acosta Pereira A, Morla R. VARIAR study: assessment of short-term efficacy and safety of rituximab compared to an tumor necrosis factor alpha antagonists as second-line drug therapy in patients with rheumatoid arthritis refractory to a first tumor necrosis factor alpha antagonist. Reumatol Clínica 2016:12:319-22.

104 Harrold LR, Reed GW, Best J, et al. Real-World comparative effectiveness of tocilizumab monotherapy vs. tumor necrosis factor inhibitors with methotrexate in patients with rheumatoid arthritis. Rheumatol Ther 2018:5:507-23.

105 Hirabara S, Takahashi N, Fukaya N, et al. Clinical efficacy of abatacept, tocilizumab, and etanercept in Japanese rheumatoid arthritis patients with inadequate response to anti-TNF monoclonal antibodies. Clin Rheumatol 2014;33:1247-54.

106 Lauper K, Nordström DC, Pavelka K, et al. Comparative effectiveness of tocilizumab versus TNF inhibitors as monotherapy or in combination with conventional synthetic disease-modifying antirheumatic drugs in patients with rheumatoid arthritis after the use of at least one biologic disease-modifying antirheumatic drug: analyses from the pan-European TOCERRA register collaboration. Ann Rheum Dis 2018;77:1276-82.

107 Vial G, De PA, Scouppe L. FRI0234 choice of biologic therapy following rituximab: influencing factors in a French multicenter cohort of rheumatoid arthritis. Ann Rheum Dis 2017;76:573.2-4.

108 Walker UA, Jaeger VK, Chatzidionysiou K, et al. Rituximab done: what's next in rheumatoid arthritis? a European observational longitudinal study assessing the effectiveness of biologics after rituximab treatment in rheumatoid arthritis. Rheumatology 2016;55:230-6.

109 Gottenberg J-E, Brocq O, Perdriger A, et al. Non-TNF-Targeted biologic vs a second anti-TNF drug to treat rheumatoid arthritis in patients with insufficient response to a first anti-TNF drug. JAMA 2016;316:1172-80.

110 Wei W, Knapp K, Wang L, et al. Treatment persistence and clinical outcomes of tumo necrosis factor inhibitor cycling or switching to a new mechanism of action therapy: real-world observational study of rheumatoid arthritis patients in the United States with prior tumor necrosis factor inhibitor therapy. Adv Ther 2017;34:1936-52.

111 González-Vacarezza N, Alemán A, González G, et al. Rituximab and tocilizumab for the treatment of rheumatoid arthritis. Int J Technol Assess Health Care 2014;30:282-8

112 Nam JL, Takase-Minegishi K, Ramiro S, et al. Efficacy of biological disease-modifying antirheumatic drugs: a systematic literature review Informing the 2016 update of the EULAR recommendations for the management of rheumatoid arthritis. Ann Rheum Dis 2017:76:1108-13.

113 Akiyama M, Kaneko Y, Kondo H, et al. Comparison of the clinical effectiveness of tumour necrosis factor inhibitors and abatacept after insufficient response to tocilizumab in patients with rheumatoid arthritis. Clin Rheumatol 2016;35:2829-34.

114 Harrold LR, Reed GW, Kremer JM, et al. The comparative effectiveness of abatacept versus anti-tumour necrosis factor switching for rheumatoid arthritis patients previously treated with an anti-tumour necrosis factor. Ann Rheum Dis 2015;74:430-6

115 Brown S, Everett CC, Naraghi K, et al. Alternative tumour necrosis factor inhibitors (TNFi) or abatacept or rituximab following failure of initial TNFi in rheumatoid arthritis: the switch RCT. Health Technol Assess 2018;22:1-280.

116 Taylor PC, Atzeni F, Balsa A, et al. The key comorbidities in patients with rheumatoid arthritis: a narrative review. J Clin Med 2021;10:509.

117 Sepriano A, Kerschbaumer A, Smolen JS, et al. Safety of synthetic and biological DMARDs: a systematic literature review Informing the 2019 update of the EULAR 
recommendations for the management of rheumatoid arthritis. Ann Rheum Dis 2020;79:760-70

118 Götestam Skorpen C, Hoeltzenbein M, Tincani A, et al. The EULAR points to consider for use of antirheumatic drugs before pregnancy, and during pregnancy and lactation. Ann Rheum Dis 2016;75:795-810.

119 Sammaritano LR, Bermas BL, Chakravarty EE, et al. 2020 American College of rheumatology guideline for the management of reproductive health in rheumatic and musculoskeletal diseases. Arthritis Rheumatol 2020:72:529-556.

120 Clowse MEB, Feldman SR, Isaacs JD, et al. Pregnancy outcomes in the tofacitinib safety databases for rheumatoid arthritis and psoriasis. Drug Saf 2016;39:755-62.

121 Hoeltzenbein M, Beck E, Rajwanshi R, et al. Tocilizumab use in pregnancy: analysis of a global safety database including data from clinical trials and post-marketing data. Semin Arthritis Rheum 2016;46:238-45.

122 Mouyis M, Flint JD, Giles IP. Safety of anti-rheumatic drugs in men trying to conceive: a systematic review and analysis of published evidence. Semin Arthritis Rheum 2019;48:911-20.

123 Nikiphorou E, Norton S, Young A, et al. The association of obesity with disease activity, functional ability and quality of life in early rheumatoid arthritis: data from the early rheumatoid arthritis Study/Early rheumatoid arthritis network UK prospective cohorts. Rheumatology 2018:57:1194-202.

124 Gremese E, Carletto A, Padovan M, et al. Obesity and reduction of the response rate to anti-tumor necrosis factor $\alpha$ in rheumatoid arthritis: an approach to a personalized medicine. Arthritis Care Res 2013;65:94-100

125 Klaasen R, Wijbrandts CA, Gerlag DM, et al. Body mass index and clinical response to infliximab in rheumatoid arthritis. Arthritis Rheum 2011;63:359-64.

126 Cantini F, Boccia S, Goletti D, et al. Hbv reactivation in patients treated with antitumor necrosis factor-alpha (TNF- $\alpha$ ) agents for rheumatic and dermatologic conditions: a systematic review and meta-analysis. Int I Rheumatol 2014;2014:926836

127 Padovan M, Filippini M, Tincani A, et al. Safety of abatacept in rheumatoid arthritis with serologic evidence of past or present hepatitis B virus infection. Arthritis Care Res 2016:68:738-43.

128 Chen L-F, Mo Y-Q, Jing J, et al. Short-Course tocilizumab increases risk of hepatitis $B$ virus reactivation in patients with rheumatoid arthritis: a prospective clinical observation. Int J Rheum Dis 2017:20:859-69.

129 Lin K-M, Cheng T-T, Lin J-C, et al. Tumor necrosis factor- $\alpha$ antagonist therapy for concomitant rheumatoid arthritis and hepatitis $\mathrm{C}$ virus infection: a case series study. Clin Rheumatol 2015;34:1039-46.

130 Brunasso AMG, Puntoni M, Gulia A, et al. Safety of anti-tumour necrosis factor agents in patients with chronic hepatitis $C$ infection: a systematic review. Rheumatology 2011:50:1700-11.

131 Rausch Osthoff A-K, Niedermann K, Braun J. EULAR recommendations for physical activity in people with inflammatory arthritis and osteoarthritis. Ann Rheum Dis 2018;2018:1251-60

132 Eversden L, Maggs F, Nightingale P, et al. A pragmatic randomised controlled trial of hydrotherapy and land exercises on overall well being and quality of life in rheumatoid arthritis. BMC Musculoskelet Disord 2007;8:23.

133 Figen $A$, Geçene M, Gündüz R. Long-Term effects of comprehensive inpatient rehabilitation on function and disease activity in patients with chronic rheumatoid arthritis and ankylosing spondylitis. Turkish J Rheumatol 2011;26:135-44.

134 Williams MA, Srikesavan C, Heine PJ, et al. Exercise for rheumatoid arthritis of the hand. Cochrane Database Syst Rev 2018;7:CD003832.

135 Lau YN, Ng J, Lee SY, et al. A brief report on the clinical trial on neural mobilization exercise for joint pain in patients with rheumatoid arthritis. Z Rheumatol 2019:78:474-8.

136 Feldthusen C, Dean E, Forsblad-d'Elia H, et al. Effects of Person-Centered physical therapy on Fatigue-Related variables in persons with rheumatoid arthritis: a randomized controlled trial. Arch Phys Med Rehabil 2016;97:26-36.

137 Macedo AM, Oakley SP, Panayi GS, et al. Functional and work outcomes improve in patients with rheumatoid arthritis who receive targeted, comprehensive occupational therapy. Arthritis Rheum 2009:61:1522-30.

138 Siqueira US, Orsini Valente LG, de Mello MT, et al. Effectiveness of aquatic exercises in women with rheumatoid arthritis: a randomized, controlled, 16-Week Intervention-The Hydra trial. Am J Phys Med Rehabil 2017;96:167-75.

139 Christie A, Jamtvedt G, Dahm KT, et al. Effectiveness of nonpharmacological and nonsurgical interventions for patients with rheumatoid arthritis: an overview of systematic reviews. Phys Ther 2007;87:1697-715

140 Hurkmans E, van der Giesen FJ, Vliet Vlieland TP. Dynamic exercise programs (aerobic capacity and/or muscle strength training) in patients with rheumatoid arthritis. Cochrane Database Syst Rev 2009:2009:CD006853.

141 Lee MS, Pittler MH, Ernst E. Tai chi for rheumatoid arthritis: systematic review. Rheumatology 2007;46:1648-51.

142 Santos EJF, Duarte C, Marques A, et al. Effectiveness of non-pharmacological and non-surgical interventions for rheumatoid arthritis: an umbrella review. JBI Database System Rev Implement Rep 2019;17:1494-531.

143 Manning VL, Hurley MV, Scott DL, et al. Education, self-management, and upper extremity exercise training in people with rheumatoid arthritis: a randomized controlled trial. Arthritis Care Res 2014;66:217-27.
144 Macfarlane GJ, Paudyal P, Doherty M, et al. A systematic review of evidence for the effectiveness of practitioner-based complementary and alternative therapies in the management of rheumatic diseases: rheumatoid arthritis. Rheumatology 2012:51:1707-13.

145 Hewlett S, Almeida C, Ambler N, et al. Group cognitive-behavioural programme to reduce the impact of rheumatoid arthritis fatigue: the raft RCT with economic and qualitative evaluations. Health Technol Assess 2019;23:1-130.

146 Ferwerda M, van Beugen S, van Middendorp H, et al. A tailored-guided Internetbased cognitive-behavioral intervention for patients with rheumatoid arthritis as an adjunct to standard rheumatological care: results of a randomized controlled trial. Pain 2017;158:868-78.

147 Dixon KE, Keefe FJ, Scipio CD, et al. Psychological interventions for arthritis pain management in adults: a meta-analysis. Health Psychol 2007:26:241-50.

148 Prothero L, Barley E, Galloway J, et al. The evidence base for psychological interventions for rheumatoid arthritis: a systematic review of reviews. Int I Nurs Stud 2018;82:20-9.

149 Dissanayake RK, Bertouch JV. Psychosocial interventions as adjunct therapy for patients with rheumatoid arthritis: a systematic review. Int I Rheum Dis 2010;13:324-34

150 Baxter SV, Hale LA, Stebbings S, et al. Walking is a feasible physical activity for people with rheumatoid arthritis: a feasibility randomized controlled trial. Musculoskeletal Care 2016:14:47-56.

151 DiRenzo D, Crespo-Bosque M, Gould N, et al. Systematic review and meta-analysis: mindfulness-based interventions for rheumatoid arthritis. Curr Rheumatol Rep 2018;20:75.

152 Hammond A, Young A, Kidao R. A randomised controlled trial of occupational therapy for people with early rheumatoid arthritis. Ann Rheum Dis 2004;63:23-30.

153 Knittle K, De Gucht V, Hurkmans E, et al. Targeting motivation and self-regulation to increase physical activity among patients with rheumatoid arthritis: a randomised controlled trial. Clin Rheumatol 2015:34:231-8.

154 Mollard E, Michaud K. A mobile APP with optical imaging for the selfmanagement of hand rheumatoid arthritis: pilot study. JMIR Mhealth Uhealth 2018:6:e12221.

155 Albano MG, Giraudet-Le Quintrec J-S, Crozet C, et al. Characteristics and development of therapeutic patient education in rheumatoid arthritis: analysis of the 2003-2008 literature. Joint Bone Spine 2010;77:405-10

156 Iversen MD, Hammond A, Betteridge N. Self-Management of rheumatic diseases: state of the art and future perspectives. Ann Rheum Dis 2010;69:955-63.

157 Srikesavan C, Bryer C, Ali U, et al. Web-Based rehabilitation interventions for people with rheumatoid arthritis: a systematic review. J Telemed Telecare 2019;25:263-75.

158 Anvar N, Matlabi H, Safaiyan A, et al. Effectiveness of self-management program on arthritis symptoms among older women: a randomized controlled trial study. Health Care Women Int 2018:39:1326-39.

159 El Miedany Y, El Gaafary M, El Arousy N, et al. Arthritis education: the integration of patient-reported outcome measures and patient self-management. Clin Exp Rheumatol 2012:30:899-904.

160 Fraenkel L, Peters E, Charpentier P, et al. Decision tool to improve the quality of care in rheumatoid arthritis. Arthritis Care Res 2012:64:977-85.

161 Fraenkel L, Matzko CK, Webb DE, et al. Use of decision support for improved knowledge, values clarification, and informed choice in patients with rheumatoid arthritis. Arthritis Care Res 2015;67:1496-502.

162 Li LC, Adam PM, Backman CL, et al. Proof-Of-Concept study of a web-based methotrexate decision aid for patients with rheumatoid arthritis. Arthritis Care Res 2014:66:1472-81.

163 Li LC, Shaw CD, Lacaille D, et al. Effects of a web-based patient decision aid on biologic and small-molecule agents for rheumatoid arthritis: results from a proof-ofconcept study. Arthritis Care Res 2018;70:343-52.

164 Taal E, Rasker JJ, Wiegman 0. Patient education and self-management in the rheumatic diseases: a self-efficacy approach. Arthritis Care Res 1996:9:229-38.

165 Barlow JH, Cullen LA, Rowe IF. Educational preferences, psychological well-being and self-efficacy among people with rheumatoid arthritis. Patient Educ Couns 2002:46:11-19.

166 Bandura A. Self-efficacy. In: the corsini encyclopedia of psychology. Hoboken, NJ, USA: John Wiley \& Sons, Inc, 2010: 1-3.

167 Lorig K, Chastain RL, Ung E, et al. Development and evaluation of a scale to measure perceived self-efficacy in people with arthritis. Arthritis Rheum 1989;32:37-44.

168 Garratt AM, Løchting I, Smedslund G, et al. Measurement properties of instruments assessing self-efficacy in patients with rheumatic diseases. Rheumatology 2014;53:1161-71

169 Gibofsky A, Galloway J, Kekow J, et al. Comparison of patient and physician perspectives in the management of rheumatoid arthritis: results from global physician- and patient-based surveys. Health Qual Life Outcomes 2018;16:211.

170 Silvers IJ, Hovell MF, Weisman MH, et al. Assessing physician/patient perceptions in rheumatoid arthritis. A vital component in patient education. Arthritis Rheum 1985:28:300-7.

171 Barlow JH, Wright CC. Knowledge in patients with rheumatoid arthritis: a longer term follow-up of a randomized controlled study of patient education leaflets. $\mathrm{Br} J$ Rheumatol 1998;37:373-6. 
172 Hosseini Moghadam M, Jahanbin I, Nazarinia MA. The effect of educational program on self-efficacy of women with rheumatoid arthritis: a randomized controlled clinical trial. Int J Community Based Nurs Midwifery 2018;6:12-20.

173 Niedermann K, de Bie RA, Kubli R, et al. Effectiveness of individual resource-oriented joint protection education in people with rheumatoid arthritis. A randomized controlled trial. Patient Educ Couns 2011;82:42-8.

174 Niedermann K, Buchi S, Ciurea A, et al. Six and 12 months' effects of individual joint protection education in people with rheumatoid arthritis: a randomized controlled trial. Scand J Occup Ther 2012;19:360-9.

175 Riemsma RP, Taal E, Brus HL, et al. Coordinated individual education with an arthritis passport for patients with rheumatoid arthritis. Arthritis Care Res 1997;10:238-49.

176 Hewlett S, Ambler N, Almeida C, et al. Self-Management of fatigue in rheumatoid arthritis: a randomised controlled trial of group cognitive-behavioural therapy. Ann Rheum Dis 2011;70:1060-7.

177 Lineker SC, Bell MJ, Wilkins AL. Improvements following short term home based physical therapy are maintained at one year in people with moderate to severe rheumatoid arthritis. J Rheumato/ 2001;28:165-8.

178 Breedland I, van Scheppingen C, Leijsma M, et al. Effects of a group-based exercise and educational program on physical performance and disease self-management in rheumatoid arthritis: a randomized controlled study. Phys Ther 2011;91:879-93.
179 Lorig KR, Ritter PL, Laurent DD, et al. The Internet-based arthritis self-management program: a one-year randomized trial for patients with arthritis or fibromyalgia. Arthritis Rheum 2008;59:1009-17.

180 Siu AMH, Chui DYY. Evaluation of a community rehabilitation service for people with rheumatoid arthritis. Patient Educ Couns 2004;55:62-9.

181 Bell MJ, Lineker SC, Wilkins AL, et al. A randomized controlled trial to evaluate the efficacy of community based physical therapy in the treatment of people with rheumatoid arthritis. J Rheumatol 1998;25:231-7.

182 Najm A, Nikiphorou E, Kostine M, et al. EULAR points to consider for the development, evaluation and implementation of mobile health applications Aiding self-management in people living with rheumatic and musculoskeletal diseases. RMD Open 2019;5:e001014.

183 Lahiri M, Luben RN, Morgan C, et al. Using lifestyle factors to identify individuals at higher risk of inflammatory polyarthritis (results from the European Prospective Investigation of Cancer-Norfolk and the Norfolk Arthritis Register--the EPIC-2-NOAR Study). Ann Rheum Dis 2014;73:219-26.

184 Fautrel B, Granger B, Combe B, et al. Matrix to predict rapid radiographic progression of early rheumatoid arthritis patients from the community treated with methotrexate or leflunomide: results from the ESPOIR cohort. Arthritis Res Ther 2012;14:R249. 